\title{
Aversão a Perdas: Comparação de Decisões de Investimento entre Investidores Individuais e Fundos de Pensão no Brasil
}

\author{
Luiz Augusto Martits* \\ William Eid Junior**
}

\begin{abstract}
Resumo
O objetivo deste artigo é analisar se o uso de uma função preferência que incorpora assimetria na reação do investidor frente a ganhos e perdas (aversão a perdas) permite gerar resultados mais coerentes com o comportamento real de investidores brasileiros, na seleção dos seus portfólios de investimento, do que uma função que não incorpora este comportamento (função utilidade tradicional). Os resultados quanto à participação do investimento em ações na composição do portfólio ótimo gerados pelos dois tipos de função são comparados com dados reais agregados de investimentos de dois tipos de investidores brasileiros (fundos de pensão e investidores individuais) visando verificar a capacidade de cada função em replicar o comportamento destes investidores. As simulações indicam que a função utilidade tradicional deve ser rejeitada como modelo representativo do comportamento dos investidores individuais, sendo este comportamento melhor representado por uma função que incorpora aversão a perdas.
\end{abstract}

Palavras-chave: maximização da utilidade; aversão a perdas; aversão ao risco; mercado acionário brasileiro; teoria da perspectiva.

Códigos JEL: G11.

\section{Abstract}

This article compares the application of a loss aversion utility function with a traditional Von Neumann-Morgenstern utility function aiming to test whether the first form of utility could better replicate the actual behavior of Brazilian investors concerning the choice of optimum investment portfolio. The results generated by both functions, in terms of stock market participation in the optimum investment portfolio, are compared with real aggregate data from two types of Brazilian investors (pension funds and individual investors). The analysis indicates that: i) the traditional utility function should be rejected as an adequate model to replicate Brazilian individual investors behavior in the stock market; and ii) Brazilian individual investors behavior are better replicated by a loss aversion utility function.

Keywords: utility maximization; loss aversion; risk aversion; Brazilian stock market; prospect theory.

Submetido em Maio de 2008. Aceito em Junho de 2009. O artigo foi avaliado segundo o processo de duplo anonimato além de ser avaliado pelo editor. Editor responsável: Ricardo P. C. Leal.

*EAESP/FGV, PUC-SP. E-mail: luiz.martits@fgv.br

**EAESP/FGV. E-mail: william.eid@fgv.br 


\section{Introdução}

$\mathrm{O}$ artigo visa testar, no mercado brasileiro, se o uso de preferências que incorporem aversão assimétrica entre ganhos e perdas (presença de aversão a perdas ou ao desapontamento) permite gerar resultados que representem melhor o comportamento dos investidores do que uma função utilidade tradicional (função utilidade na forma proposta por Von Neumann e Morgenstern (1944)) em termos de participação do mercado acionário no portfólio ótimo de investimentos. Conforme já antecipado por alguns autores, além da incapacidade em incorporar o comportamento previsto no Paradoxo de Allais (Allais, 1953) entre outras violações dos axiomas da teoria da utilidade esperada, a função utilidade tradicional também não permite acomodar em seus resultados decisões de investimento onde o investidor apresenta baixas taxas de investimento no mercado acionário (Ang et alii, 2005). A maior flexibilidade do modelo de preferência com aversão a perdas indica ser este um modelo mais adequado para acomodar os diversos tipos de comportamento presentes no mercado brasileiro.

O foco do artigo será especificamente em dois tipos de investidores, que serão melhor caracterizados mais adiante: investidor individual e fundos de pensão. Dados agregados de investimentos no mercado financeiro brasileiro sugerem que os investidores individuais investiram, no período de 1997 a 2006, entre 6,1\% e $17,9 \%$ do seu portfólio agregado em ações. Por outro lado, dados da ABRAPP (Associação Brasileira das Entidades Fechadas de Previdência Complementar) indicam que, no mesmo período, os fundos de pensão brasileiros aplicaram, em média, entre $27,0 \%$ e $41,4 \%$ de sua carteira de investimentos em renda variável (mercado acionário e fundos de renda variável), sugerindo uma aversão ao risco sensivelmente menor por parte destes investidores institucionais.

$\mathrm{O}$ modelo testado parte da premissa de que o investidor possui duas alternativas de investimento (ativo com risco e ativo sem risco) e busca maximizar a utilidade gerada pelo seu portfólio de investimentos através da composição ótima do ativo com risco (mercado acionário, referenciado pelo Ibovespa) e do ativo sem risco (títulos do governo, referenciados pela taxa CDI). O modelo pressupõe ainda que o investidor reavalia seus investimentos uma vez ao ano e toma decisões sobre os investimentos nestes horizontes de decisão com base nas suas expectativas de risco e retorno para os dois ativos mencionados acima.

Especificamente, são duas as hipóteses testadas neste artigo:

Hipótese nula $\left(H_{0}\right)$ : O comportamento agregado dos investidores brasileiros quanto à taxa de investimento no mercado acionário é adequadamente representado por uma função utilidade na sua forma tradicional (que só leva em conta a aversão ao risco de segunda ordem).

Hipótese alternativa $\left(H_{1}\right)$ : $\mathrm{O}$ comportamento agregado dos investidores brasileiros quanto à taxa de investimento no mercado acionário é melhor representado por uma função preferência que incorpora aversão a perdas (aversão ao risco de primeira ordem) do que por uma função utilidade na sua forma tradicional. 
A adequação de cada função será testada com base na análise dos parâmetros resultantes da otimização de cada função que permitem gerar resultados equivalentes às taxas reais de investimento em ações dos investidores no mercado brasileiro para o período de 1997 a 2006. No caso da função utilidade tradicional, o parâmetro a ser verificado será a aversão ao risco de segunda ordem $(\gamma)$ e no caso da função preferência com aversão a perdas, os parâmetros a serem verificados serão a própria aversão ao risco de segunda ordem $(\gamma)$ e a aversão a perdas $(D)$. Caso as taxas reais de investimento em ações possam ser replicadas utilizando-se graus aceitáveis de aversão ao risco (no caso da função utilidade tradicional), a hipótese $H_{0}$ não é rejeitada. No caso da hipótese $H_{1}$, a rejeição ou não dependerá da combinação de aversão ao risco $(\gamma)$ e aversão a perdas $(D)$ estarem ou não na região de rejeição, conforme apresentado na descrição da metodologia mais adiante.

O restante deste artigo está dividido da seguinte forma: a Seção 2 detalha a metodologia dos testes de hipótese. A Seção 3 descreve resumidamente o perfil dos investidores analisados. A Seção 4 apresenta os resultados dos testes de hipótese e a Seção 5 apresenta as principais contribuições deste artigo e suas implicações.

\section{Metodologia}

Os modelos testados de maximização de utilidade pressupõem as seguintes premissas:

1. O investidor possui duas opções de investimento: ativo com risco (mercado acionário) e ativo sem risco (CDI);

2. Conforme embasamento teórico de Benartzi e Thaler (1995), o investidor reavalia seus investimentos com freqüência anual e realoca seu portfólio de investimentos no fim de cada período com base nas suas expectativas de retorno e risco para o período seguinte;

3. O investidor não faz venda à descoberto do ativo com risco (ações), assim como não toma dinheiro emprestado para investir mais do que $100 \%$ do seu portfólio no ativo com risco;

4. A composição anual do portfólio de investimentos é definida com o objetivo de maximizar a utilidade gerada pelo portfólio no final do horizonte de decisão, supondo dois modelos alternativos de preferência, conforme abaixo:

Modelos de maximização testados:

1. Função utilidade tradicional:

$$
\operatorname{Max}_{(\alpha)} E[U(W)]
$$

Tal que: 


$$
E[U(W)]=\int_{-\infty}^{\infty} U(W) d F(W)
$$

e

$$
U(W)=\frac{W^{1-\gamma}}{1-\gamma}
$$

Sujeito à:

$$
W=1+(1-\alpha) r_{f}+\alpha r_{m}
$$

2. Função preferência com aversão a perdas (ou ao desapontamento):

$$
\operatorname{Max}_{(\alpha)} E[U(W, V r)]
$$

Tal que:

$$
E[U(W, V r)]=\frac{1}{K}\left(\int_{-\infty}^{V r} U(W) d F(W)+D \int_{V r}^{+\infty} U(W) d F(W)\right)
$$

e

$$
U(W)=\frac{W^{1-\gamma}}{1-\gamma}
$$

Sujeito à:

$$
W=1+(1-\alpha) r_{f}+\alpha r_{m}
$$

onde $r_{f}=$ retorno do ativo sem risco $(\mathrm{CDI}) ; r_{m}=$ retorno do ativo com risco (Ibovespa); $\alpha=$ percentual investido no ativo com risco; $\gamma=$ coeficiente de aversão ao risco (de segunda ordem); $D=$ coeficiente de aversão a perdas ou ao desapontamento $(D \leq 1) ; V r=$ valor referencial para diferenciar ganhos e perdas $F(W)$ = função distribuição cumulativa do retorno do investimento (assumida como sendo uma distribuição normal); $K=\operatorname{Probabilidade}(W<$ $V r)+D$ x Probabilidade $(W>V r)$

A forma de ponderação da função preferência com aversão a perdas é similar àquela adotada no artigo de Ang et alii (2005). No entanto, ao contrário do critério adotado por estes autores, o valor referencial $(V r)$ para diferenciar ganhos de perdas não é o equivalente-certo, que apresenta dificuldades computacionais por ser uma variável endógena ao problema, mas sim a riqueza inicial $\left(W_{0}\right)$ mais o retorno do ativo livre de risco, conforme metodologia adotada por Barberis et alii 
(2001). Enquanto Ang et alii (2005) utilizam o embasamento axiomático de Gul (1991) para justificar o uso do equivalente-certo como valor referencial para diferenciar ganhos e perdas, Barberis et alii (2001) utilizam uma variável exógena ao problema de maximização (a riqueza inicial mais o retorno do ativo livre de risco), tendo por base evidências comportamentais, como aquelas apresentadas no artigo de Kahneman e Tversky (1979).

Apesar do uso de um valor referencial diferente daquele usado por Ang et alii (2005) ser uma mudança estrutural no modelo, alterando sua lógica e invalidando o raciocínio axiomático que o embasa (note que o embasamento axiomático dado por Gul (1991), que sustenta o modelo de Ang et alii (2005), supõe um modelo que tenha como valor referencial o equivalente-certo), o modelo aqui proposto não é incompatível com a teoria de otimização de carteiras e com a principal premissa que a sustenta, qual seja, de racionalidade do investidor. Ainda que o modelo aqui aplicado seja descritivo, sua importância está exatamente em permitir verificar se a flexibilização de um modelo normativo e a incorporação de variáveis comportamentais permitem replicar de forma mais adequada o comportamento de diferentes tipos de investidor. A simples aplicação do modelo de Ang et alii (2005) na sua forma original não permitiria avançar na discussão da validade de modelos com diferentes formas de proposição. É importante enfatizar que a presença de aversão a perdas na função utilidade, seja ela definida de forma axiomática ou não, não é incompatível com o comportamento de um investidor que busca maximizar a relação entre retorno e risco. Na realidade, o coeficiente de aversão a perdas simplesmente acrescenta uma variável que dá maior peso a perdas do que aos ganhos comparativamente a uma função utilidade tradicional. E, mesmo que não seja sustentada por um embasamento axiomático, isto não implica que seja incompatível com a premissa de racionalidade e outras que sustentam a teoria de decisões de investimento e otimização de carteiras.

A função utilidade na forma potência foi selecionada por apresentar preferências do tipo CRRA (Constant Relative Risk Aversion), tendo sido extensamente utilizada em artigos acadêmicos, como no próprio artigo de Ang et alii (2005).

O horizonte de decisão anual se refere ao período em que o investidor reavalia seus investimentos, e não ao horizonte em que este planeja usufruir dos seus resultados. Esta diferenciação entre horizontes de avaliação e de usufruto, que é feita por Kahneman e Tversky (1979) na aplicação da teoria da perspectiva e também é utilizada por Benartzi e Thaler (1995), é importante em modelos comportamentais, pois, mesmo que o investidor usufrua dos resultados dos seus investimentos só na sua aposentadoria, este avalia e calcula a utilidade dos retornos em períodos menores, e realoca seus investimentos nestes períodos de reavaliação.

\section{Determinação de parâmetros aceitáveis}

Ainda que a determinação de parâmetros aceitáveis de aversão ao risco não seja um processo que resulte em respostas absolutas, não sendo possível identificar com clareza a partir de que grau a aversão ao risco se torna rejeitável de 
forma mais contundente, alguns artigos dão indicações de quais intervalos podem ser considerados razoáveis. Friend e Blume (1975), por exemplo, analisaram dados de consumidores norte-americanos e acharam evidências de que o comportamento destes investidores pode ser melhor replicado por graus de aversão ao risco $(\gamma)$ em torno de 2, mas trabalharam com uma função quadrática. Mehra e Prescott (1985) utilizam uma função utilidade do tipo CRRA e mencionam vários trabalhos, inclusive de Arrow (1971), cujos resultados sugerem como razoáveis graus de aversão ao risco entre 0 e 2. Benartzi e Thaler (1995) mencionam como razoáveis graus de aversão ao risco em torno de 1 .

\section{Aversão ao risco}

A determinação de parâmetros adequados para os graus de aversão ao risco e aversão a perdas neste artigo é feita com base nas loterias de Rabin (2000), metodologia aplicada também por Ang et alii (2005). Esta metodologia apresenta como vantagens a possibilidade de simular diferentes variações representativas em relação à riqueza inicial do investidor e interpretar de forma mais fácil o comportamento implícito em cada grau de aversão ao risco. Com base nesta metodologia, é possível identificar quais níveis de aversão ao risco (ou a perdas) implicam em comportamentos exagerados quando trazidos para um conjunto de decisões mais simples.

A determinação dos limites máximos aceitáveis para os coeficientes de aversão ao risco $(\gamma)$ e aversão a perdas $(D)$ será feita através da identificação dos coeficientes que resultam na rejeição de loterias onde as possibilidades de ganho são infinitamente altas e as de perda reduzidas, loterias estas cuja rejeição não seriam economicamente aceitáveis para a grande maioria dos investidores em condições normais de decisão de investimento.

Considere uma loteria onde o investidor aplica $\$ 1,00$ e tem os dois cenários possíveis abaixo e suas respectivas probabilidades (o valor da riqueza inicial não interfere nos resultados já que se trata de uma função CRRA):

Cenário 1: riqueza final de $R_{1}$ (probabilidade=50\%) Cenário 2: riqueza final de $\$ 0,90$ (probabilidade $=50 \%$ )

As figuras do Apêndice I apresentam a utilidade resultante deste tipo de loteria para diferentes valores de payoff no cenário $1\left(R_{1}\right)$ e para diferentes graus de aversão ao risco $(\gamma)$, supondo que o investidor possui uma função utilidade na forma tradicional de ponderação. Nota-se pelas figuras do apêndice que, para $\gamma \geq 8$, o investidor rejeitará esta loteria, independentemente do payoff do cenário 1. Ou seja, um investidor com este grau de aversão ao risco jamais aceitaria apostar em um jogo onde tem $50 \%$ de chance de perder $10 \%$ da sua riqueza, mesmo que o cenário positivo (e com a mesma probabilidade) lhe ofereça ganhos infinitos. Este resultado mostra que o comportamento representado por $\gamma \geq 8$ reflete um grau de aversão ao risco muito elevado, e que dificilmente poderia ser considerado aceitável em situações normais de decisão de investimento. 
O irrealismo deste comportamento pode ser melhor compreendido se considerarmos que o investidor pode dividir sua riqueza em parcelas iguais e investir estas $\mathrm{n}$ parcelas em n loterias equivalentes à loteria acima. Suponha, por exemplo, que o retorno da loteria no cenário 1 seja de $100 \%$, ou seja, $R_{1}=2,0$ (o retorno no cenário 1 poderia ser maior, já que o investidor rejeitaria até mesmo loterias que tenham payoff infinito neste cenário). Supondo que o investidor divida sua riqueza em cinco porções iguais, teremos que o retorno $\mathrm{x}$ deste conjunto de cinco loterias tem um valor esperado, dado por $E(x)=r_{1} p+r_{2}(1-p)$, de $E(x)=45,0 \%$, enquanto a probabilidade do investidor obter um retorno final negativo, dada por $(1-p)^{5}$, é de apenas $3,1 \%$ (já que o saldo final conjunto das cinco loterias só será negativo se todas as cinco loterias gerarem o cenário 2). E, mesmo que o cenário 2 ocorra para as cinco loterias, o investidor perderá apenas $10 \%$ da sua riqueza.

Ainda que a loteria anterior permita determinar que $\gamma \geq 8$ representa um grau de aversão ao risco extremamente elevado, não deixa claro as implicações de considerar valores inferiores a $\gamma=8$ que, conforme indicado por alguns artigos, podem representar graus também elevados. Visando dar maior abrangência no critério de rejeição das hipóteses testadas, decidiu-se classificar o grau de rejeição em quatro níveis:

- Rejeição forte: graus de aversão ao risco que implicam na rejeição da loteria acima com possibilidade de perda de $10 \%$ no cenário ruim, por melhor que seja o retorno do cenário bom;

- Rejeição média: graus de aversão ao risco que implicam na rejeição da loteria acima com possibilidade de perda de $15 \%$ no cenário ruim, por melhor que seja o retorno do cenário bom;

- Rejeição fraca: graus de aversão ao risco que implicam na rejeição da loteria acima com possibilidade de perda entre $20 \%$ e $30 \%$ no cenário ruim, por melhor que seja o retorno do cenário bom;

- Não-rejeição: graus de aversão ao risco que não geram rejeição da loteria de forma independente do retorno no cenário bom.

Utilizando a lógica acima, chegou-se à seguinte classificação quanto à rejeição dos graus de aversão ao risco: rejeição forte: $\gamma \geq 7$; rejeição média: $5<\gamma \leq 7$; rejeição fraca: $2<\gamma \leq 5$; não-rejeição: $\gamma \leq 2$.

É importante observar que a função utilidade tradicional pressupõe inexistência de aversão a perdas. Portanto, para o teste da hipótese $H_{0}$, é necessário avaliar apenas o coeficiente de aversão ao risco $(\gamma)$, assumindo que a aversão a perdas $(D)$ é sempre igual a 1 (quando $D=1$, os retornos acima ou abaixo do valor referencial têm o mesmo peso, não havendo portanto aversão a perdas). 


\section{Aversão a perdas}

A determinação de parâmetros aceitáveis para a função preferência com aversão a perdas (teste da hipótese $H_{1}$ ) segue o mesmo critério de classificação apresentado acima na determinação de parâmetros aceitáveis para o coeficiente de aversão ao risco $(\gamma)$. A figura abaixo apresenta a classificação das diversas combinações de aversão ao risco $(\gamma)$ e aversão a perdas $(D)$ de acordo com os quatro graus de rejeição propostos anteriormente:

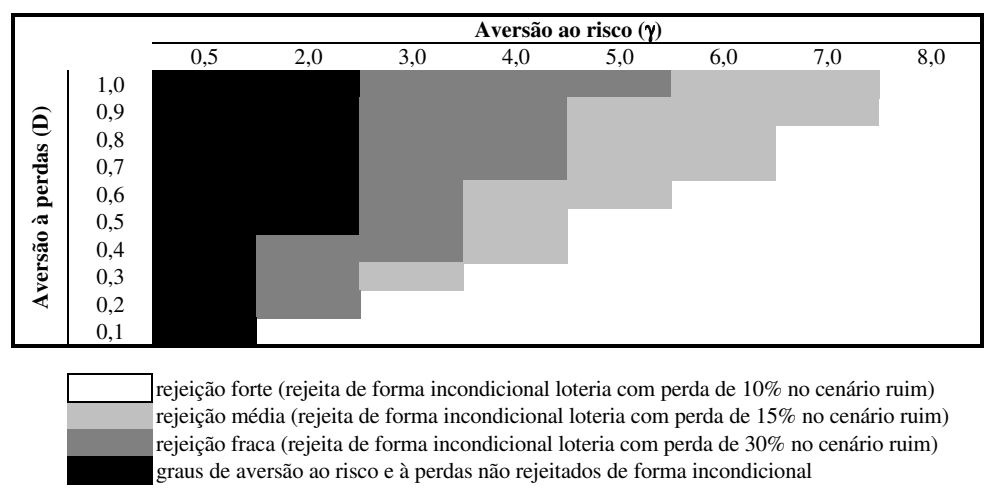

Figura 1

Parâmetros aceitáveis de aversão ao risco e aversão a perdas

A figura acima pode ser interpretado da seguinte forma: a região em branco representa graus inaceitáveis de aversão ao risco e a perdas pois supõe um tipo de investidor que rejeitaria de forma incondicional uma loteria com 50\% de probabilidade de perder $10 \%$ da sua riqueza, mesmo que tenha probabilidades infinitas de ganhos no cenário bom. Como esta reação representa um tipo de comportamento inaceitável para a grande maioria dos investidores, ele é rejeitado de forma forte. No caso dos outros graus de rejeição, o que muda é o tipo de loteria rejeitada, que representam um comportamento de menor aversão, mas ainda bastante elevado e de pouca aceitação.

A determinação da rejeição ou não de cada tipo de loteria para cada combinação de aversão ao risco $(\gamma)$ e aversão a perdas $(D)$ foi feito através da comparação entre o equivalente-certo de jogar cada loteria e o equivalente-certo de não jogar. Os resultados apresentados na tabela são, portanto, de situações onde o equivalente-certo de não jogar cada tipo de loteria testado era maior do que jogálas, por maior que fosse o retorno no cenário bom (rejeição incondicional). 
Apesar do critério de rejeição acima ser subjetivo, é importante ressaltar, conforme descrito anteriormente nesta seção, que vários autores já indicaram, no caso de uma função utilidade tradicional, que graus de aversão ao risco razoáveis se situam entre 0 e 2 , e que valores acima de $\gamma=2$ são considerados elevados.

\section{Caracterização dos Investidores}

\section{Investidor Pessoa Física (Investidor Individual)}

O investidor pessoa física (ou investidor individual), do ponto de vista deste artigo, é caracterizado como o agente decisor que investe sua própria riqueza, sendo o principal prejudicado ou beneficiado por eventuais variações negativas ou positivas no seu patrimônio decorrentes das suas decisões de investimento. Apesar da possibilidade de intermediação e influência de terceiros no seu processo decisório (e.g., gerentes de banco, administradores de fundos, conselheiros de investimentos, etc), a responsabilidade pela decisão final é totalmente sua, e o patrimônio envolvido, em última instância, é essencialmente o seu próprio. O investidor pessoa física é o equivalente ao termo em inglês "household", comumente utilizado em microeconomia como a unidade básica de análise quanto às decisões de consumo e poupança. O investidor pessoa física se contrapõe ao investidor institucional, caracterizado como uma pessoa jurídica que administra o patrimônio de terceiros e recebe uma comissão ou taxa de administração por este tipo de serviço (e.g., fundos de pensão, fundos de investimento, fundos de private equity, etc).

Para efeito da análise da composição agregada do portfólio destes investidores, considerou-se apenas algumas categorias de investimento que representam a maior parte do patrimônio das aplicações financeiras destes investidores: i) poupança, ii) $\underline{\text { fundos de investimento, }}$ iii) $\underline{\mathrm{CDB}}$ e iv) investimento direto em ações. Estas quatro categorias de investimento se caracterizam como as principais opções de investimento em ativos financeiros disponíveis à maior parte da população. Outros tipos de aplicações financeiras têm baixa representatividade sobre o total investido por pessoas físicas, e sua exclusão não impacta nos resultados dos modelos. Este artigo se restringe apenas à analise da composição da carteira de investimento em ativos financeiros, pressupondo que as decisões de investimento em ativos nãofinanceiros (imóveis, por exemplo) não influem na composição do portfólio de investimentos financeiros.

Ao contrário dos dados de composição dos portfólios dos fundos de pensão, que são publicados e disponibilizados ao público em geral, facilitando o trabalho de coleta e estimação de dados, a estimação da composição do portfólio agregado dos investidores individuais é dificultada pela inexistência de dados específicos para este tipo de investidor. Para contornar esta dificuldade, a estimação da composição do portfólio destes investidores foi feita em três etapas: i) estimação do patrimônio total anual de cada categoria de ativo listada acima; ii) estimação da participação dos investidores individuais em cada categoria; iii) estimação do alfa anual (investimento em ações sobre patrimônio total dos investimentos financeiros 
dos investidores individuais). Para estimação do alfa, o investimento em ações foi estimado como a soma do investimento direto em ações e fundos de ações sobre o total do patrimônio de investimentos financeiros.

As quatro diferentes categorias de investimento consideradas acima tiveram que ser classificadas em um dos dois tipos de ativo assumidos como premissas dos modelos: ativo com risco e ativo sem risco. Os parágrafos a seguir descrevem o critério de classificação e sua justificativa:

A poupança, apesar de oferecer um rendimento abaixo da taxa CDI (taxa considerada como referência para o ativo livre de risco no modelo testado neste artigo), é considerada uma opção de investimento menos arriscada que os investimentos em títulos do governo, e portanto pode ser classificada como ativo livre de risco. O fato do seu rendimento estar historicamente abaixo da taxa CDI poderia gerar dúvidas quanto à adequação da sua classificação como um ativo que rende taxa CDI, podendo causar viés nos resultados de otimização dos modelos testados. Neste caso, no entanto, como o rendimento da poupança é menor que o CDI, ao se supor que o investimento em poupança rende a taxa CDI, o viés do modelo será um resultado de participação do ativo com risco (ações) no portfólio ótimo abaixo do que seria esperado para cada nível de aversão ao risco (ou a perdas) caso se estivesse utilizando o rendimento da poupança. A rejeição da hipótese nula, neste caso, será mais difícil de ocorrer (teste de hipótese mais conservador), pois será exigido um menor grau de aversão ao risco para justificar baixos índices de participação do ativo com risco no portfólio ótimo.

No caso dos fundos de investimento, a classificação entre investimentos atrelados à renda fixa e à renda variável foi feita com base em percentual anual informado pela própria ANBID (Associação Nacional dos Bancos de Investimento). A base de dados de fundos de investimento da ANBID engloba fundos de renda fixa, fundos DI, fundos abertos de previdência privada, fundos multimercado e fundos cambiais, entre outros.

Os Certificados de Depósito Bancário (CDBs) foram assumidos como referenciados pela taxa CDI.

Os investimentos diretos na bolsa representam a maior dificuldade na estimação da composição final do portfólio dos investidores pessoa física, uma vez que os dados de participação dos investidores individuais na capitalização de mercado bursátil são poucos e superficiais, exigindo a estimação com base em números secundários, como participação no volume negociado, composição da estrutura acionária das maiores empresas, volume de ADRs, etc. Dada a subjetividade envolvida neste processo de estimação, preferiu-se trabalhar com intervalos ao invés de valores absolutos anuais. Desta forma, apesar da menor precisão dos valores apresentados na forma de intervalos, eles são mais confiáveis no sentido de compreenderem estas variações decorrentes da subjetividade das estimações.

O valor do investimento direto em ações dos investidores individuais foi calculado com base na participação destes investidores no free-float médio de cada ano, multiplicado pela capitalização de mercado anual média da bolsa. O free-float 
médio do mercado acionário foi estimado com base na média do free-float das maiores empresas (empresas que compõem o Ibovespa), ponderados pela participação de cada empresa na capitalização total da bolsa. O free-float individual de cada empresa, por sua vez, foi estimado da seguinte forma:

Volume total de ações - qtd ações dos grupos de controle - qtd ações negociadas na forma de ADRs

Volume total de ações

Este critério resultou em um free-float médio entre $25 \%$ e $35 \%$ do valor de mercado das empresas negociadas na Bovespa.

Sobre este valor, foi multiplicado o percentual que os investidores individuais representaram do volume negociado em cada ano, informado pela Bovespa. Este critério resultou em valores entre 2,9\% (1997) e 8,5\% (2004) de participação direta dos investidores individuais no total da capitalização de mercado da bolsa quando utilizado o teto de $35 \%$ de free-float. Esta baixa participação resulta do pouco interesse apresentado pelos investidores individuais em investir diretamente no mercado acionário até recentemente (note-se, no entanto, que além destes investimentos diretos, os investidores têm investimentos indiretos através dos fundos de ações) e mostra que grande parte dos investimentos em ações no Brasil ainda tem como origem outros tipos de investidores, como investidores institucionais e instituições financeiras (entre eles, os próprios fundos de pensão e os fundos de investimento), participações da União, estados e municípios, participações do BNDES, investidores estrangeiros e famílias que participam dos grupos de controle das empresas de capital aberto.

O cálculo do alfa real dos investidores individuais não inclui as participações das famílias que compõem os grupos de controle das empresas de capital aberto, pois estes investimentos são considerados de prazo muito longo e se diferenciam do processo decisório da grande maioria de investidores, cuja decisão não está sujeita às implicações da necessidade de manter grande parte do patrimônio em uma mesma empresa visando manter seu poder de voto.

A decisão de excluir as participações das famílias controladoras do cálculo do alfa real dos investidores individuais poderia ser contestada com base no fato de que estes investimentos (i.e., vinculados aos grupos de controle de empresas) não foram excluídos na estimação do alfa real agregado dos fundos de pensão. No entanto, como os fundos de pensão concentram um valor elevado de ativos sob sua administração, a participação elevada em algumas empresas é uma decorrência do tamanho do seu patrimônio individual, e não representam necessariamente uma decisão pontual de concentrar seus ativos em uma ou poucas empresas. $\mathrm{O}$ caso do fundo Previ, que participa do grupo de controle de várias empresas, é um exemplo claro desta situação: mesmo com investimentos distribuídos entre várias empresas, o grande patrimônio sob sua administração (em torno de R $\$ 106$ bilhões no final de 2006) lhe possibilita fazer parte do grupo de controle de algumas empresas das quais participa. 
Adicionalmente, tendo em vista que o objetivo dos testes de hipótese é identificar a função preferência que melhor replica o comportamento médio dos dois tipos de investidores, no caso dos investidores individuais a exclusão das famílias que participam dos grupos de controle das empresas se justifica pelo fato destas representarem uma minoria em relação à população total dos investidores individuais, mas cuja representatividade em termos de ativos investidos em ações geraria resultados viesados nos testes de hipótese. No caso dos fundos de pensão, a participação elevada em algumas empresas decorre do grande patrimônio individual destes investidores, e não de uma decisão específica de concentrar grande parte do patrimônio próprio em uma única empresa. O processo decisório das famílias controladoras se dá também de forma diferente do investidor comum: além de ser um investimento de longo prazo, a família controladora possui um forte vínculo com a empresa, sendo normalmente um dos seus fundadores. A venda de participação implicaria em perda de controle e a conseqüente mudança na capacidade da família em comandar e influenciar as decisões estratégicas da empresa, e de se beneficiar das implicações deste controle. O impacto é portanto muito maior, e o processo decisório muito diferente, do que a realocação de investimentos de um investidor comum, que busca apenas uma melhor relação retorno/risco, sem as implicações advindas do controle da empresa.

A figura abaixo apresenta os valores mínimo e máximo estimados de participação do investimento em ações (alfa) no portfólio agregado anual dos investidores pessoa física para o período de 1997 a 2006. Conforme ressaltado anteriormente, o uso de intervalos se deve à dificuldade em se estimar o valor investido em algumas opções de investimento, sendo calculados através da estimação de algumas variáveis, o que gera um intervalo de valores possíveis ao invés de um número absoluto. A participação das ações no portfólio é calculada como a soma do investimento direto em ações e fundos de ações dividida pelo total dos investimentos financeiros. 


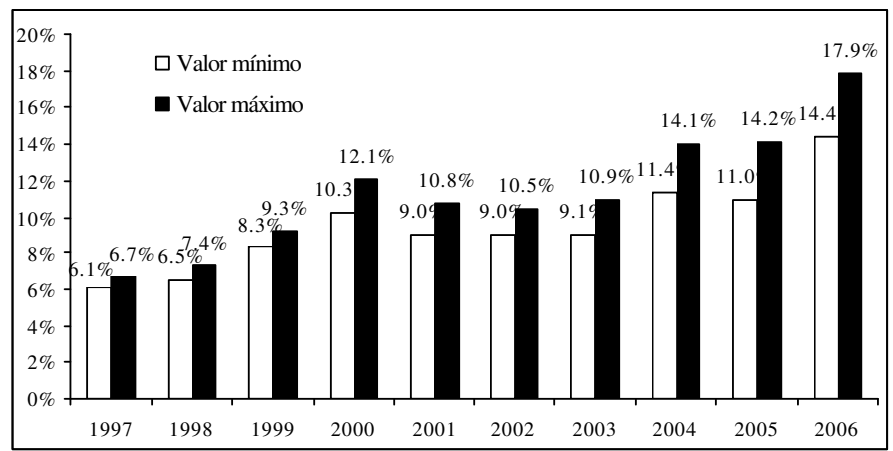

Fontes: ANBID, CETIP, IPEAData, Bovespa.

Estimação do investimento agregado em ações: dados trabalhados pelos autores.

Figura 2

Participação das ações no portfólio agregado de investidores individuais

\section{Fundos de Pensão}

Foram considerados como fundos de pensão todas as entidades fechadas de previdência complementar cujo objetivo é oferecer uma aposentadoria complementar à oferecida pelo sistema público. O fundo Previ, dos funcionários do Banco do Brasil, representava em 2007 em torno de 28\% do total de recursos administrados por fundos de pensão brasileiros, tendo portanto uma representatividade bastante significativa. Por esta razão, e devido à sua forte participação no mercado acionário brasileiro, a análise do resultado dos testes mais à frente foi feita considerando-se o comportamento agregado dos fundos de duas formas: incluindo-se e excluindo-se o fundo Previ.

No período de 1997 a 2006, os investimentos em ações representaram entre $27 \%$ e $41 \%$ do total dos ativos destes fundos. No entanto, ao se excluir o fundo Previ, a taxa de investimento em ações cai para valores entre $17 \%$ e $28 \%$, conforme as figuras abaixo: 

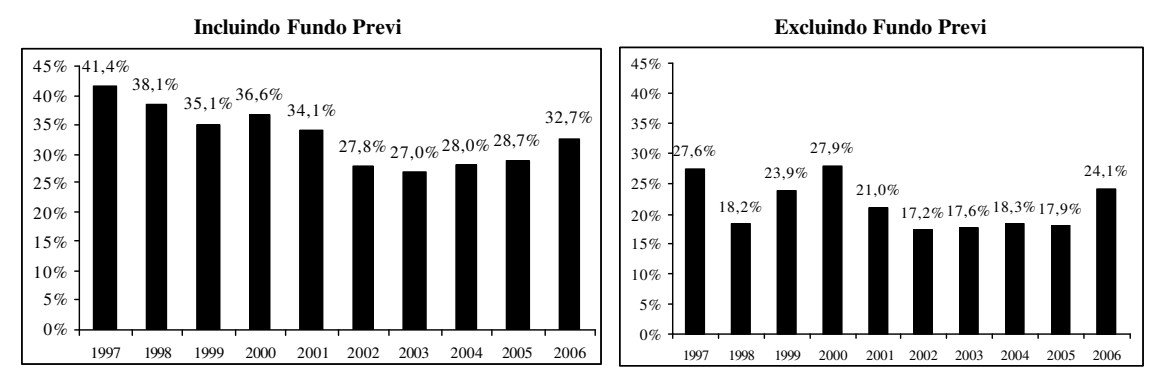

Figura 3

Participação dos investimentos em ações na carteira agregada dos fundos de pensão

\section{Testes das Hipóteses}

\section{Premissas}

Os testes das hipóteses $H_{0}$ e $H_{1}$ foram efetuados utilizando-se a seguinte metodologia para estimar as expectativas de retorno e risco para cada ano:

- Retorno do ativo livre de risco: expectativa quanto à taxa CDI anual estimada com base no retorno embutido em contratos futuros em negociação na $\mathrm{BM} \& \mathrm{~F} ;$

- Risco (desvio-padrão) do mercado acionário: estimado através do método EWMA (Exponentially Weighted Moving Average);

- Prêmio pelo risco de mercado: estimado pelo índice de Sharpe.

Para a expectativa de retorno anual do ativo livre de risco (CDI), foi utilizado o retorno embutido nos contratos futuros de taxa de juros (DI) negociados na BM\&F com vencimentos mais próximos à data da decisão (ou seja, os primeiros vencimentos de cada ano).

A tabela abaixo apresenta os retornos anuais nominais esperados do CDI estimados com base na metodologia descrita acima, assim como o valor do CDI deflacionado pela inflação prevista em cada ano e as taxas anuais realizadas do CDI (para comparação): 
Tabela 1

Expectativa de rendimento anual do ativo livre de risco (CDI)

\begin{tabular}{lcccccccccc}
\hline \multicolumn{1}{c}{ Ano } & 1997 & 1998 & 1999 & 2000 & 2001 & 2002 & 2003 & 2004 & 2005 & 2006 \\
\hline $\begin{array}{l}\text { CDI estimado } \\
\text { nominal* }\end{array}$ & $21,82 \%$ & $35,59 \%$ & $27,94 \%$ & $18,25 \%$ & $14,94 \%$ & $18,02 \%$ & $24,24 \%$ & $15,20 \%$ & $17,05 \%$ & $16,32 \%$ \\
\hline $\begin{array}{l}\text { Inflação } \\
\text { estimada** }\end{array}$ & $7,50 \%$ & $5,00 \%$ & $7,00 \%$ & $6,40 \%$ & $4,34 \%$ & $4,84 \%$ & $13,24 \%$ & $5,92 \%$ & $6,08 \%$ & $4,46 \%$ \\
\hline $\begin{array}{l}\text { CDI estimado real } \\
\text { (deflacionado) }\end{array}$ & $13,32 \%$ & $29,13 \%$ & $19,57 \%$ & $11,13 \%$ & $10,16 \%$ & $12,57 \%$ & $9,72 \%$ & $8,76 \%$ & $10,35 \%$ & $11,35 \%$ \\
\hline
\end{tabular}

(deflacionado)

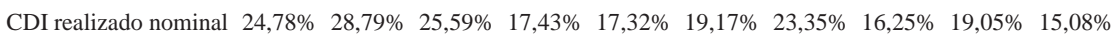
* Estimativa com base nos contratos futuros de DI negociados na BM\&F no início de cada ano. Fonte: BM\&F ** Inflação estimada no início de cada ano. Fonte: relatórios do Banco Central e IPEAData (1999 a 2006), dados do autor (1997 e 1998).

Os dados utilizados nas simulações são as taxas estimadas deflacionadas do CDI, uma vez que o objetivo é identificar o portfólio ótimo sem considerar o efeito da inflação no processo decisório do investidor.

Para a estimação da expectativa de risco (desvio-padrão) do mercado acionário para cada ano foi utilizada a metodologia do EWMA (Exponentially Weighted Moving Average), uma média móvel das observações históricas que permite dar maior peso aos eventos mais recentes. Conforme metodologia aplicada pelo banco J.P. Morgan (Riskmetrics Group, 1996), a volatilidade do retorno de um ativo pode ser estimada da seguinte forma:

$$
\sigma_{t}^{2}=E W M A=(1-\lambda) \sum_{j=1}^{L} \lambda^{j-1} r_{t-j}^{2}
$$

onde $\sigma_{t}^{2}=$ previsão da variância para $t ; \lambda=$ fator de decaimento; $r_{t-j}=$ retorno do período $t-j ; L=$ número de observações consideradas.

Através da minimização dos erros ao quadrado de previsão da volatilidade dos retornos do Ibovespa para o período de 1997-2006, encontrou-se um fator de decaimento de $\lambda=0,91$. Para estimar este fator, foram consideradas todas observações mensais de retorno desde 1974 até o mês anterior a cada ano que se deseja prever o desvio-padrão. Assim, a fórmula do EWMA apresentada acima foi utilizada para prever o desvio-padrão do retorno mensal, e este desvio-padrão foi posteriormente anualizado pela fórmula $D P_{\text {anual }}=D P_{\text {mensal }} \times \sqrt{12}$. Este critério permitiu utilizar uma base histórica maior, necessária para a aplicação desta metodologia.

A tabela a seguir apresenta o desvio-padrão anualizado previsto pelo EWMA, assim como o desvio-padrão anualizado estimado com base nas variações mensais do Ibovespa de cada ano do período de 1997 a 2006. Os valores do retorno do Ibovespa utilizados para cálculo do desvio-padrão foram deflacionados pelo IPCFIPE. 
Tabela 2

Desvio-padrão realizado e estimado

\begin{tabular}{ccccccccccc}
\hline Ano & 1997 & 1998 & 1999 & 2000 & 2001 & 2002 & 2003 & 2004 & 2005 & 2006 \\
\hline Desvio-padrão realizado * & $41,0 \%$ & $59,1 \%$ & $35,3 \%$ & $30,5 \%$ & $34,2 \%$ & $35,2 \%$ & $23,9 \%$ & $18,1 \%$ & $27,9 \%$ & $20,6 \%$ \\
\hline Desvio-padrão estimado ** & $46,6 \%$ & $44,6 \%$ & $56,3 \%$ & $49,9 \%$ & $38,5 \%$ & $34,8 \%$ & $36,0 \%$ & $33,4 \%$ & $24,5 \%$ & $25,4 \%$ \\
\hline * Desvio-padrão anualizado do retorno mensal deflacionado.
\end{tabular}

* Desvio-padrão anualizado do retorno mensal deflacionado.

** Estimado pelo método EWMA.

Quanto à estimação do prêmio pelo risco, o uso do índice de Sharpe tem a vantagem de não se basear apenas em dados históricos, que pecam por não permitir incorporar expectativas futuras. A metodologia adotada neste artigo segue uma lógica similar àquela utilizada por Friend e Blume (1975), onde o alfa ótimo (e o grau de aversão relativa ao risco) é determinado em função da relação retorno/risco oferecida pelo ativo com risco. Christelis et alii (2006) também estimam a participação do mercado acionário no portfólio ótimo como função do índice de Sharpe. Por ser calculado em função das expectativas de retorno do CDI e do risco de mercado, esta metodologia não gera cenários distorcidos onde o prêmio é muito baixo ou até negativo, caso em que os investidores não investiriam no mercado acionário. Este tipo de distorção pode ocorrer quando se utiliza modelos de previsão onde as estimativas de risco e prêmio pelo risco não estão vinculadas, como o método dos dividendos descontados. Desta forma, com o índice de Sharpe a estimativa de retorno de mercado fica restrita à análise e à discussão de patamares adequados de um único índice.

Foram utilizados três valores para o índice de Sharpe (IS): $I S=0,15, I S=$ 0,2 e $I S=0,3$, tendo como referência os prêmios historicamente pagos pelo mercado brasileiro, conforme apresentado na tabela abaixo, que apresenta os dados históricos calculados com base na média aritmética dos retornos anuais deflacionados. Através desta tabela é possível observar que o índice de Sharpe no Brasil se situou no intervalo entre 0,16 e 0,28.

Tabela 3

Mensuração do índice de sharpe no Brasil

\begin{tabular}{cccccc}
\hline \multirow{2}{*}{ Período } & \multicolumn{2}{c}{ Retorno Médio } & Desvio & & Índice de \\
\cline { 2 - 5 } & Ibovespa & CDI & Ibovespa & Prêmio & Sharpe \\
\hline $1974-2006$ & $31,10 \%$ & $9,90 \%$ & $84,20 \%$ & $21,20 \%$ & 0,25 \\
\hline $1974-1996$ & $34,80 \%$ & $7,90 \%$ & $95,80 \%$ & $26,90 \%$ & 0,28 \\
\hline $1997-2006$ & $22,70 \%$ & $14,50 \%$ & $51,80 \%$ & $8,10 \%$ & 0,16 \\
\hline
\end{tabular}

Quanto ao uso da média aritmética, ela se justifica pelo objetivo do artigo, que é estimar expectativas de curto prazo (um ano). De forma geral, quando o objetivo é estimar retornos no longo prazo, os autores apresentam desvantagens tanto para a média aritmética como para a média geométrica: enquanto o uso da média aritmética tem o defeito de superestimar os retornos no longo prazo, a média geométrica tem o defeito inverso, de subestimar os retornos de longo prazo (Blume, 1974). Apesar de não haver um consenso para estimativas de longo prazo, diversos autores consideram adequado o uso da média aritmética quando se tratam 
de estimativas de curto prazo. Damodaran (1999), por exemplo, sugere que a média aritmética é adequada para estimativas de prêmio pelo risco de curto prazo, mas ressalta que se os retornos históricos forem negativamente correlacionados, a média aritmética tenderá a superestimar o prêmio pelo risco no longo prazo, sendo então mais adequada a média geométrica. Varga (2001) reforça a adequação do uso da média aritmética para períodos intermediários (ou de curto prazo) em contrapartida ao uso da média geométrica para análises de longo prazo. Blume (1974) mostra que quanto menor o horizonte de investimento $(N)$ vis-à-vis o horizonte da amostra histórica $(T)$, maior é a adequação da média aritmética. No limite mínimo, quando $N=1$, a média aritmética é a forma correta de estimar os retornos.

Os critérios adotados acima geraram o seguinte conjunto de expectativas para os retornos anuais de cada ano:

Tabela 4

Conjunto de premissas para os testes de hipótese

\begin{tabular}{|c|c|c|c|c|c|}
\hline \multirow[b]{2}{*}{ Ano } & \multicolumn{3}{|c|}{ Retorno Mercado } & \multirow{2}{*}{$\begin{array}{c}\text { Retorno } \\
\text { CDI }\end{array}$} & \multirow{2}{*}{$\begin{array}{c}\text { Risco Mercado } \\
\text { (Desvio-Padrão) }\end{array}$} \\
\hline & $(\mathrm{IS}=0,15)$ & $(\mathrm{IS}=0,20)$ & $(\mathrm{IS}=0,30)$ & & \\
\hline 1997 & $20,3 \%$ & $22,6 \%$ & $27,3 \%$ & $13,3 \%$ & $46,6 \%$ \\
\hline 1998 & $35,8 \%$ & $38,1 \%$ & $42,5 \%$ & $29,1 \%$ & $44,6 \%$ \\
\hline 1999 & $28,0 \%$ & $30,8 \%$ & $36,5 \%$ & $19,6 \%$ & $56,3 \%$ \\
\hline 2000 & $18,6 \%$ & $21,1 \%$ & $26,1 \%$ & $11,1 \%$ & $49,9 \%$ \\
\hline 2001 & $15,9 \%$ & $17,8 \%$ & $21,7 \%$ & $10,2 \%$ & $38,5 \%$ \\
\hline 2002 & $17,8 \%$ & $19,5 \%$ & $23,0 \%$ & $12,6 \%$ & $34,8 \%$ \\
\hline 2003 & $15,1 \%$ & $16,9 \%$ & $20,5 \%$ & $9,7 \%$ & $36,0 \%$ \\
\hline 2004 & $13,8 \%$ & $15,4 \%$ & $18,8 \%$ & $8,8 \%$ & $33,4 \%$ \\
\hline 2005 & $14,0 \%$ & $15,2 \%$ & $17,7 \%$ & $10,3 \%$ & $24,5 \%$ \\
\hline 2006 & $15,2 \%$ & $16,4 \%$ & $19,0 \%$ & $11,4 \%$ & $25,4 \%$ \\
\hline
\end{tabular}

IS = Índice de Sharpe.

\section{Resultados}

O Apêndice II no final deste artigo apresenta os resultados das simulações de maximização com as premissas apresentadas na tabela acima. Os percentuais apresentados nas figuras do Apêndice II se referem ao alfa ótimo para diferentes cenários de premissas e diferentes combinações de aversão ao risco $(\gamma)$ e aversão a perdas $(D)$. São apresentados três grupos de tabelas no Apêndice II, considerando os três cenários de prêmio pelo risco assumidos: i) índice de Sharpe de 0,15, ii) índice de Sharpe de 0,2 e iii) índice de Sharpe de 0,3. Comparando-se as taxas de investimento agregadas reais anuais dos investidores pessoa física e dos fundos de pensão no período de 1997 a 2006 (apresentadas respectivamente nas figuras 1 e 2) com os alfas ótimos apresentados no Apêndice II, é possível chegar às seguintes conclusões: 
i) A função utilidade tradicional (hipótese $H_{0}$ ) não é rejeitada como modelo representativo do comportamento agregado dos fundos de pensão com o fundo Previ no cenário que assume índice de Sharpe de 0,15 , exceto nos anos de 2005 e 2006, quando é rejeitada na forma fraca;

ii) Quando se assume índice de Sharpe de 0,2, a função utilidade tradicional é rejeitada na forma fraca em vários anos como modelo representativo do comportamento agregado dos fundos de pensão com o fundo Previ;

iii) Quando se assume índice de Sharpe de 0,3, a função utilidade tradicional é rejeitada na forma fraca em todos anos como modelo representativo do comportamento agregado dos fundos de pensão com o fundo Previ;

iv) A função utilidade tradicional é rejeitada na forma fraca como modelo representativo do comportamento agregado dos fundos de pensão quando se exclui o fundo Previ nos cenários com $I S=0,15$ e $I S=0,2$ e é rejeitada na forma média quando se pressupõe expectativas de prêmio pelo risco mais elevadas $(I S=0,3)$;

v) A função utilidade tradicional é rejeitada na forma forte como modelo representativo do comportamento agregado dos investidores individuais (hipótese $H_{0}$ ) quando assumido cenário com índice de Sharpe de 0,3 (em praticamente todos anos seria necessário um grau de aversão ao risco maior do que 7 para justificar o comportamento agregado dos investidores para este cenário);

vi) A função utilidade tradicional é rejeitada nas formas média ou fraca quando se assume cenários com índice de Sharpe de 0,2 e 0,15, ainda que não atinja em nenhum ano a região de não-rejeição;

vii) Não é possível rejeitar a função preferência com aversão a perdas como modelo representativo do comportamento agregado dos investidores individuais (hipótese $H_{1}$ ) em nenhum dos três cenários assumidos para o índice de Sharpe.

A tabela abaixo resume as conclusões acima em relação à hipótese $H_{0}$ (adequação da função utilidade tradicional em replicar o comportamento dos dois investidores). Os resultados da hipótese $H_{1}$ não são mostrados uma vez que a adequação da função utilidade com aversão a perdas nunca é rejeitada. 
Tabela 5

Níveis de rejeição da hipótese $H_{0}$

\begin{tabular}{|c|c|c|c|}
\hline \multirow[b]{2}{*}{ Tipo de Investidor } & \multicolumn{3}{|c|}{ Cenário (Índice de Sharpe) } \\
\hline & 0,15 & 0,20 & 0,30 \\
\hline $\begin{array}{c}\text { Fundos de pensão } \\
\text { com Previ }\end{array}$ & $\begin{array}{l}H_{0} \text { rejeitada } \\
\text { forma fraca }\end{array}$ & $\begin{array}{l}H_{0} \text { rejeitada } \\
\text { forma fraca }\end{array}$ & $\begin{array}{l}H_{0} \text { rejeitada } \\
\text { forma fraca }\end{array}$ \\
\hline $\begin{array}{c}\text { Fundos de pensão } \\
\text { sem Previ }\end{array}$ & $\begin{array}{l}H_{0} \text { rejeitada } \\
\text { forma fraca }\end{array}$ & $\begin{array}{l}H_{0} \text { rejeitada } \\
\text { forma fraca }\end{array}$ & $\begin{array}{l}H_{0} \text { rejeitada } \\
\text { forma média }\end{array}$ \\
\hline $\begin{array}{l}\text { Pessoas físicas } \\
\text { (média agregada) }\end{array}$ & $\begin{array}{l}H_{0} \text { rejeitada } \\
\text { forma média }\end{array}$ & $\begin{array}{l}H_{0} \text { rejeitada } \\
\text { forma média }\end{array}$ & $\begin{array}{l}H_{0} \text { rejeitada } \\
\text { forma forte }\end{array}$ \\
\hline
\end{tabular}

A conclusão (i) acima decorre do fato de que é possível replicar as taxas de investimento anuais em ações dos fundos de pensão (quando incluído o fundo Previ) com graus de aversão ao risco $(\gamma)$ iguais ou menores do que $\gamma=2 \mathrm{em}$ praticamente todos anos para o cenários com índice de Sharpe de 0,15 . Já nos cenários com índice de Sharpe de 0,2 e 0,3, no entanto, o grau de aversão ao risco que justifica a taxa real agregada de investimento em ações dos fundos de pensão se situa na região de rejeição fraca $(2<\gamma \leq 5)$.

A conclusão (iv), que trata da análise do comportamento agregado dos fundos de pensão excluindo-se o fundo Previ, segue a mesma lógica. A diferença é que há rejeição fraca inclusive no cenário que assume um prêmio pelo risco menor (índice de Sharpe de 0,15). Adicionalmente, no cenário que assume índice de Sharpe de 0,3 , há rejeição em níveis mais fortes da função utilidade tradicional, uma vez que os alfas reais dos fundos só seriam replicados com graus de aversão ao risco acima de $\gamma=5$ em alguns anos (rejeição média), sugerindo que o comportamento de alguns fundos de pensão, de forma individual, poderia ser melhor justificado por uma função com aversão a perdas.

A comparação das tabelas do Apêndice II com a Figura 2 (que apresenta as taxas anuais de investimento em ações dos investidores individuais) mostra que a Hipótese $H_{0}$ (teste de adequação da função utilidade tradicional) pode ser facilmente rejeitada para os investidores individuais, uma vez que não é possível replicar o comportamento destes investidores com graus de aversão ao risco $(\gamma)$ menores ou iguais a $5 \mathrm{em}$ quase nenhum cenário ou ano, sugerindo que a função utilidade tradicional, que não incorpora aversão a perdas (i.e., $D=1$ ), não é um modelo adequado para replicar o comportamento real dos investidores individuais no período analisado.

Por outro lado, é possível notar, com base no Apêndice II, que a função preferência com aversão a perdas permite gerar resultados coerentes com o comportamento real dos investidores individuais nos 10 anos da amostra para os três cenários de expectativas de prêmio pelo risco: os níveis reais de investimento dos investidores individuais no mercado acionário podem ser replicados por uma função preferência com aversão a perdas que tenha coeficiente de aversão ao risco de $\gamma=2$ e coeficiente de aversão a perdas $(D)$ entre 0,5 e 0,9 , dentro portanto da região de não-rejeição. Outras combinações de aversão ao risco $(\gamma)$ e aversão 
a perdas $(D)$ também permitem gerar resultados similares ao comportamento real dos investidores individuais no período da amostra, mas se situam em regiões com maior nível de rejeição (note que o intervalo para $\gamma$ e $D$ mencionado acima se situa na região onde não há rejeição da hipótese $H_{1}$ em nenhum nível, conforme parâmetros definidos na Seção 2).

\section{Conclusão}

Ainda que a função preferência com aversão a perdas já tenha sido objeto de análise de várias trabalhos, e mais recentemente alguns deles no Brasil, o presente artigo adiciona novas informações ao utilizar dados reais de retorno e risco do mercado brasileiro, e basear a análise em taxas reais de investimento dos dois grupos de investidores, permitindo a comparação direta entre os dois tipos de função e as duas categorias de investidores. Outros artigos normalmente focam em um único tipo de investidor, e a metodologia utilizada normalmente se baseia em testes de laboratório ou em modelos teóricos. Desta forma, este artigo complementa e adiciona algumas informações novas aos trabalhos efetuados recentemente por outros autores no Brasil (e.g., Pessoa et alii (2007); Iglesias et alii (2006)) que, de forma geral, compartilham a idéia central de que a função preferência com aversão a perdas apresenta algumas qualidades não presentes na função utilidade tradicional.

Este artigo contribui ainda na forma de modelagem da função preferência com aversão a perdas, uma combinação do modelo de Ang, Bekaert e Liu (2005) com a premissa de valor referencial de Barberis, Huang e Santos (2001). Ainda que o modelo de preferência com aversão a perdas tenha uma representação matemática muito similar ao modelo de Ang et alii (2005), difere deste pelo fato de utilizar um valor referencial que não é o equivalente-certo, permitindo o uso de valores referenciais mais próximos da realidade dos investidores e da sua forma de raciocinar. Desta forma, ao utilizar a taxa livre de risco como valor referencial, distancia-se do suporte axiomático proposto por Gul (1991) e Ang et alii (2005). Por outro lado, o modelo não pressupõe gosto pelo risco na região das perdas conforme modelo proposto por Tversky e Kahneman (1992), indicando que esta premissa não é condição necessária para que a função preferência com aversão a perdas se apresente como um modelo adequado para representar o comportamento dos investidores individuais.

Em termos microeconômicos, os resultados dos testes de hipótese corroboram com vários outros trabalhos na linha de aversão a perdas e teoria comportamental, a partir dos quais fica mais clara a inadequação de uma função utilidade tradicional e a necessidade de se aprimorá-la de forma a acomodar comportamentos que não são coerentes com seus axiomas. Mais especificamente, a presença de aversão a perdas implica que a sensibilidade do investidor a riscos não está vinculada apenas à aversão à variância, mas também à rejeição mais exarcebada de cenários com retornos não satisfatórios. Desta forma, fundos de investimento com estratégias que permitam reduzir estes cenários (através do uso de derivativos, por exemplo) podem ser mais atrativos aos olhos dos investidores individuais do que 
fundos com prêmios pelo risco equivalentes, mas que atinjam cenários identificados como "perdas" com maior frequiência. De certa forma, as opções de investimentos em ações com proteção contra perdas (como o produto POP - Proteção do Investimento com Participação lançado pela Bovespa) estão fazendo exatamente isto: diminuindo as possibilidades de cenários ruins, ainda que isto implique na diminuição de ganhos em cenários bons, atraindo assim uma nova parcela de investidores com maior aversão a perdas.

No caso dos investidores individuais, se por um lado a função preferência com aversão a perdas supõe maior aversão para cenários com retornos abaixo do valor referencial, por outro lado o comportamento destes investidores se mostra mais elástico para mudanças de expectativas quanto ao risco de mercado e o prêmio pelo risco. Supondo uma melhora na relação retorno/risco do mercado acionário (por exemplo, queda do desvio-padrão do retorno de mercado de $40 \%$ para $32 \%$ e prêmio pelo risco estável em $8 \%$ ), e considerando um investidor médio que apresente aversão ao risco de $\gamma=2,0$ e aversão a perdas de $D=0,7$, seria esperado um aumento em torno de 1.100 pontos-base na taxa de investimento média em ações por parte destes investidores - um investidor que tenha $8 \%$ de seu portfólio em ações, por exemplo, aumentaria esta participação para aproximadamente $19 \%$ como resposta a esta mudança de expectativa (mais do que dobrando portanto o investimento em ações). Em contrapartida, um investidor que não apresente aversão a perdas, e tenha aversão ao risco de $\gamma=2,0$, reagiria com um aumento de 1.500 pontos-base na taxa de investimento em ações, passando de um alfa de $28 \%$ para um alfa de $43 \%$. Assim, ainda que o crescimento em termos de pontos-base do investidor com aversão a perdas seja menor, seu crescimento relativo é maior.

Provavelmente, a melhor explicação para esta diferença na forma de tomar uma decisão de investimentos decorra da proximidade ou intensidade que o impacto da decisão tem para cada investidor. Como o administrador de um fundo de pensão não está administrando seu próprio patrimônio, seu processo decisório fica menos sujeito à rejeição de cenários negativos, desde que estes cenários negativos tenham a possibilidade de serem recuperados no longo prazo. Os investidores individuais, por outro lado, sofrem com maior intensidade em decorrência de variações negativas na sua riqueza, pois elas representam uma redução diretamente proporcional na sua capacidade de consumo. Desta forma, cenários com retornos ruins são rejeitados de forma mais intensa por um investidor individual do que por um investidor que toma decisões relacionadas à riqueza de terceiros. Mesmo que os cenários negativos tenham possibilidade de serem recuperados, o sofrimento pela perda de riqueza para o investidor individual provavelmente não compensa a espera de retornos positivos no longo prazo, daí a rejeição mais forte dos cenários negativos na forma proposta pela função preferência com aversão a perdas.

Ainda que a forma de classificação dos graus de aversão ao risco e aversão a perdas utilizados neste artigo sejam subjetivos, eles partem de parâmetros já apresentados por outros autores. De fato, é difícil ignorar que alguns graus de rejeição são intuitivamente extremados, como pôde ser visto nos resultados das aplicações 
destes graus de aversão (ao risco e a perdas) nas loterias de Rabin. Supor, por exemplo, que graus de aversão ao risco $(\gamma)$ maiores do que 5 sejam aceitáveis para o comportamento médio do investidor, significa supor que estes investidores, na média, iriam rejeitar aquele conjunto de loterias apresentados anteriormente, uma premissa bastante extremada para o comportamento médio agregado dos investidores - ainda que eventualmente aceitável para o comportamento individual de um ou outro investidor. Adicionalmente, outros artigos, mesmo que não tenham determinado de forma objetiva quais são os níveis aceitáveis de aversão ao risco, dão indicações de que graus de aversão ao risco $(\gamma)$ acima de 2 já podem ser considerados bastante elevados. No caso específico dos investidores individuais, parece muito mais razoável supor um comportamento de aversão a perdas do que um comportamento extremado de aversão à variância.

Mesmo que a análise deste artigo não permita compreender com maiores detalhes o processo decisório de cada indivíduo a partir dos dados agregados, ela permite antecipar que, uma vez rejeitada a adequação da função utilidade tradicional para os dados agregados, é possível rejeitá-la como modelo adequado também para o nível de decisão individual, ao menos para a maior parte dos investidores (caso contrário, não seria possível rejeitar o comportamento agregado, já que este representa a média do comportamento dos indivíduos isolados). Exemplificando, suponha uma economia composta por apenas dois investidores individuais, $I_{1}$ e $I_{2}$, respectivamente com $20 \%$ e $80 \%$ do total de ativos. Caso o alfa real (participação das ações no portfólio ótimo) agregado destes investidores individuais seja de 7\%, a hipótese $\mathrm{H}_{0}$ seria rejeitada para o comportamento agregado destes investidores na maioria dos anos/cenários. Neste caso, a análise agregada poderia ser criticada por não permitir interpretar o comportamento individual de cada um dos dois investidores, $I_{1}$ e $I_{2}$, mas certamente a rejeição da hipótese $H_{0}$ continuaria válida para pelo menos um dos investidores. Caso o alfa real do investidor $I_{1}$ seja, por exemplo, de $35 \%$, a hipótese $H_{0}$ não seria rejeitada especificamente para este investidor, mas certamente seria rejeitada para o investidor $I_{2}$ (que, por dedução, tem alfa real de $0 \%$ ). É fácil notar que esta lógica é válida para qualquer combinação de alfas, quantidade de investidores e percentuais de participação na economia. De fato, no exemplo acima é possível rejeitar $H_{0}$ para ambos investidores para várias combinações de alfa real e participação na economia, mas sob nenhuma condição é possível aceitar a hipótese $H_{0}$ para todos investidores enquanto a hipótese $H_{0}$ for rejeitada para o alfa agregado.

Os resultados dos testes de hipótese deste artigo devem ser interpretados dentro das limitações impostas pelas premissas assumidas no desenvolvimento dos modelos. Mais especificamente, três características dos cálculos e das premissas para modelagem apresentam limitações e poderiam ser aprimorados:

(i) A estimação do alfa real (taxa real de investimento agregado em ações) dos investidores individuais apresentou dificuldades devido à falta de dados agregados de investimento que identificassem a participação de cada tipo de investidor em cada tipo de investimento. Assim, do total do investi- 
mento em poupança, $\mathrm{CDBs}$ e fundos de investimento, foi necessário estimar intervalos de percentual de participação dos investidores individuais nestes investimentos, gerando possibilidade de erro nesta estimação. A adoção de um intervalo de percentuais para estimação do alfa real $(\alpha)$ conforme apresentado no artigo, ao invés do uso de um valor específico, permitiu contornar este problema parcialmente ao definir patamares mínimo é máximo para esta variável. No entanto, caso se comprove que o alfa real dos investidores individuais esteja fora do intervalo estimado, acarretaria mudanças nas conclusões em relação à rejeição ou não das hipóteses testadas;

(ii) A segunda restrição se refere à forma de definição dos intervalos de rejeição para as diferentes combinações de aversão ao risco $(\gamma)$ e aversão a perdas $(D)$, conforme resumido na Figura 1. O critério adotado não é matemático, não seguindo a normatização rígida destes modelos, estando portanto mais suscetível à contestação. Ainda que as loterias de Rabin dêem uma boa indicação da razoabilidade das implicações de cada combinação possível de $\gamma$ e $D$, elas são essencialmente intuitivas e baseadas no bom senso. A aceitação dos resultados dos testes de hipótese será tanto maior quanto mais razoável for aceitar que as loterias de Rabin, na forma proposta, representam um comportamento adequado que pode servir de referência para determinar o que se espera de um investidor médio;

(iii) A terceira limitação se refere à forma de estimação das premissas de retorno e risco do ativo com risco, baseadas no histórico de prêmio pelo risco pago pelo mercado acionário brasileiro. A maximização da utilidade pressupõe a definição de estatísticas relacionadas à distribuição dos retornos dos ativos. No entanto, ao desenvolver um modelo descritivo, a premissa de que os investidores, e principalmente o investidor individual, assumem uma distribuição normal para o ativo com risco pode ser contestada com base na forma que as decisões de investimento são feitas por investidores individuais, normalmente de forma intuitiva e referenciadas em um conjunto de informações provavelmente pouco organizadas, e dificilmente com base em dados estatisticamente calculados. Ainda que o processo decisório do investidor individual seja de difícil modelagem, e a premissa de distribuição normal não reflita necessariamente a realidade deste processo, os resultados dos testes mostram que a função com aversão a perdas permite identificar falhas na premissa de que a ponderação dada pela função utilidade tradicional é inadequada e, neste sentido, acreditamos que outros tipos de distribuição que tentem replicar o comportamento real dos ativos, ou a forma que os investidores processam esta informação, irão gerar resultados similares àqueles aqui encontrados no que tange a presença de aversão a perdas. 


\section{Referências}

Allais, M. (1953). Le comportement de l'homme rationnel devant le risque: Critique des postulats et axiomes de l'ecole americaine. Econometrica, 21.

Ang, A., Bekaert, G., \& Liu, J. (2005). Why stocks may disappoint. Journal of Financial Economics, 76.

Arrow, K. J. (1971). Essays in the theory of risk-bearing. North-Holland, Amsterdam.

Barberis, N., Huang, M., \& Santos, T. (2001). Prospect theory and asset prices. The Quarterly Journal of Economics, 116.

Benartzi, S. \& Thaler, R. (1995). Myopic loss aversion and the equity premium puzzle. The Quarterly Journal of Economics, 110.

Blume, M. E. (1974). Unbiased estimators of long-run expected rates of return. Journal of the American Statistical Association, 69.

Christelis, D., Jappelli, T., \& Padula, M. (2006). Cognitive abilities and portfolio choice. CSEF (Centre for Studies in Economics and Finance). Working paper n. 157.

Damodaran, A. (1999). Estimating equity risk premiums. Stern School of Business.

Friend, I. \& Blume, M. E. (1975). The demand for risky assets. The American Economic Review, 65.

Gul, F. (1991). A theory of disappointment aversion. Econometrica, 59.

Iglesias, M. C., Battisti, J. E. Y., \& Pacheco, J. M. (2006). O comportamento do investidor brasileiro na alocação de ativos. Anais do 6o Encontro Brasileiro de Finanças, Vitória.

Kahneman, D. \& Tversky, A. (1979). Prospect theory: An analysis of decision under risk. Econometrica, 47.

Mehra, R. \& Prescott, E. (1985). The equity premium: A puzzle. Journal of Monetary Economics, 15.

Pessoa, P., Bonomo, M., \& Garcia, R. (2007). Reproduzindo os momentos dos retornos dos ativos brasileiros com aversão a desapontamento generalizada. Anais do 7o Encontro Brasileiro de Finanças, São Paulo.

Rabin, M. (2000). Risk aversion and expected utility theory: A calibration theorem. Econometrica, 68. 
Riskmetrics Group (1996). RiskMetrics - technical document. J. P. Morgan/Reuters.

Tversky, A. \& Kahneman, D. (1992). Advances in prospect theory: Cumulative representation of uncertainty. Journal of Risk and Uncertainty, 5.

Varga, G. (2001). índice de sharpe e outros indicadores de performance aplicados a fundos de ações brasileiros. Revista de Administração Contemporânea, 5(3).

Von Neumann, J. \& Morgenstern, O. (1944). Theory of Games and Economic Behavior. Princeton University Press. 


\section{Apêndice I}
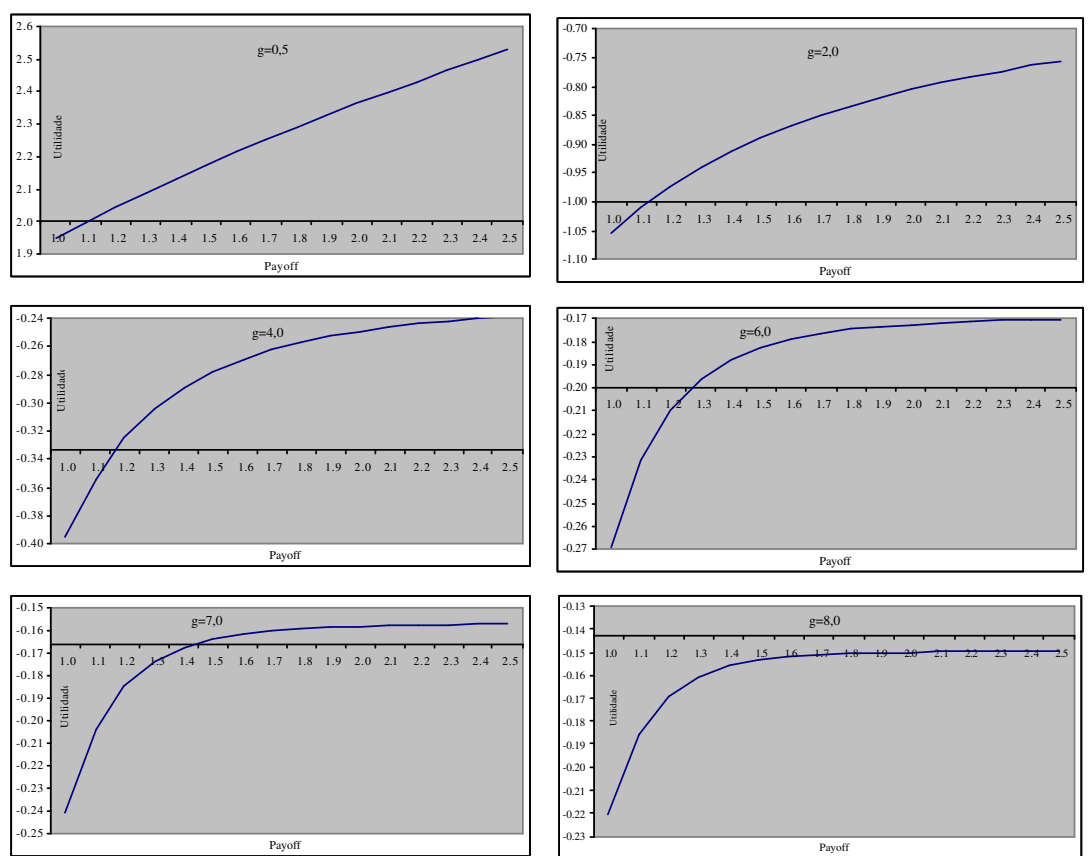

Notas:

Os gráficos mostram a utilidade da loteria de Rabin que tem os payoffs para o cenário 1 apresentados no eixo $\mathrm{x}$, e as seguintes características:

- Investimento inicialde

- cenário 1: payoff apresentado no eixo x com probabilidade de 50\%

- cenário 2: payoff de 0,90 com probabilidade de $50 \%$

$\mathrm{O}$ local onde $\mathrm{o}$ eixo $\mathrm{x}$ cruza o eixo y nos gráficos equivale à utilidade de não apostar na loteria e manter a riqueza inicial. Assim, os trechos das curvas de utilidade abaixo do eixo $\mathrm{x}$ representam as situações onde o investidor prefere manter sua riqueza ao invés de apostar na loteria.

Figura A.1

Gráficos referenciais para determinação de parâmetros aceitáveis de aversão ao risco $(\gamma)$ - grau de rejeição forte 
Apêndice II

\begin{tabular}{|c|c|c|c|c|c|c|c|c|c|c|c|c|c|c|c|}
\hline 1997 & & & & $\gamma$ & & & & 2002 & & & & $\gamma$ & & & \\
\hline D & 0.5 & 2 & 3 & 4 & 5 & 6 & 7 & D & 0.5 & 2 & 3 & 4 & 5 & 6 & 7 \\
\hline 1.0 & $73.7 \%$ & $19.9 \%$ & $13.3 \%$ & $10.0 \%$ & $8.0 \%$ & $6.6 \%$ & $5.7 \%$ & 1.0 & $91.1 \%$ & $24.8 \%$ & $16.6 \%$ & $12.4 \%$ & $9.9 \%$ & $8.3 \%$ & $7.1 \%$ \\
\hline 0.9 & $56.0 \%$ & $14.5 \%$ & $9.7 \%$ & $7.3 \%$ & $5.8 \%$ & $4.8 \%$ & $4.1 \%$ & 0.9 & $69.0 \%$ & $17.9 \%$ & $12.0 \%$ & $9.0 \%$ & $7.2 \%$ & $6.0 \%$ & $5.1 \%$ \\
\hline 0.8 & $33.5 \%$ & $8.4 \%$ & $5.6 \%$ & $4.2 \%$ & $3.4 \%$ & $2.8 \%$ & & 0.8 & $40.5 \%$ & $10.2 \%$ & $6.8 \%$ & $5.1 \%$ & $4.1 \%$ & $3.4 \%$ & \\
\hline 0.7 & $6.2 \%$ & $1.6 \%$ & $1.0 \%$ & $0.8 \%$ & $0.6 \%$ & $0.5 \%$ & & 0.7 & $5.8 \%$ & $1.4 \%$ & $1.0 \%$ & $0.7 \%$ & $0.6 \%$ & $0.5 \%$ & \\
\hline 0.6 & $0.0 \%$ & $0.0 \%$ & $0.0 \%$ & $0.0 \%$ & $0.0 \%$ & & & 0.6 & $0.0 \%$ & $0.0 \%$ & $0.0 \%$ & $0.0 \%$ & $0.0 \%$ & & \\
\hline 0.5 & $0.0 \%$ & $0.0 \%$ & $0.0 \%$ & $0.0 \%$ & & & & 0.5 & $0.0 \%$ & $0.0 \%$ & $0.0 \%$ & $0.0 \%$ & & & \\
\hline 0.4 & $0.0 \%$ & $0.0 \%$ & $0.0 \%$ & $0.0 \%$ & & & & 0.4 & $0.0 \%$ & $0.0 \%$ & $0.0 \%$ & $0.0 \%$ & & & \\
\hline 0.3 & $0.0 \%$ & $0.0 \%$ & $0.0 \%$ & & & & & 0.3 & $0.0 \%$ & $0.0 \%$ & $0.0 \%$ & & & & \\
\hline 0.2 & $0.0 \%$ & $0.0 \%$ & & & & & & 0.2 & $0.0 \%$ & $0.0 \%$ & & & & & \\
\hline 0.1 & $0.0 \%$ & & & & & & & 0.1 & $0.0 \%$ & & & & & & \\
\hline 1998 & & & & $\bar{\gamma}$ & & & & 2003 & & & & $\bar{\gamma}$ & & & \\
\hline 1.0 & $81.6 \%$ & $22.2 \%$ & $14.8 \%$ & $11.1 \%$ & $8.9 \%$ & $7.4 \%$ & $6.4 \%$ & 1.0 & $85.8 \%$ & $23.3 \%$ & $15.6 \%$ & $11.7 \%$ & $9.4 \%$ & $7.8 \%$ & $6.7 \%$ \\
\hline 0.9 & $61.8 \%$ & $16.1 \%$ & $10.7 \%$ & $8.0 \%$ & $6.4 \%$ & $5.4 \%$ & $4.6 \%$ & 0.9 & $65.0 \%$ & $16.9 \%$ & $11.3 \%$ & $8.5 \%$ & $6.8 \%$ & $5.6 \%$ & $4.8 \%$ \\
\hline 0.8 & $36.3 \%$ & $9.2 \%$ & $6.1 \%$ & $4.6 \%$ & $3.7 \%$ & $3.0 \%$ & & 0.8 & $38.1 \%$ & $9.6 \%$ & $6.4 \%$ & $4.8 \%$ & $3.8 \%$ & $3.2 \%$ & \\
\hline 0.7 & $5.2 \%$ & $1.3 \%$ & $0.9 \%$ & $0.6 \%$ & $0.5 \%$ & $0.4 \%$ & & 0.7 & $5.5 \%$ & $1.4 \%$ & $0.9 \%$ & $0.7 \%$ & $0.5 \%$ & $0.5 \%$ & \\
\hline 0.6 & $0.0 \%$ & $0.0 \%$ & $0.0 \%$ & $0.0 \%$ & $0.0 \%$ & & & 0.6 & $0.0 \%$ & $0.0 \%$ & $0.0 \%$ & $0.0 \%$ & $0.0 \%$ & & \\
\hline 0.5 & $0.0 \%$ & $0.0 \%$ & $0.0 \%$ & $0.0 \%$ & & & & 0.5 & $0.0 \%$ & $0.0 \%$ & $0.0 \%$ & $0.0 \%$ & & & \\
\hline 0.4 & $0.0 \%$ & $0.0 \%$ & $0.0 \%$ & $0.0 \%$ & & & & 0.4 & $0.0 \%$ & $0.0 \%$ & $0.0 \%$ & $0.0 \%$ & & & \\
\hline 0.3 & $0.0 \%$ & $0.0 \%$ & $0.0 \%$ & & & & & 0.3 & $0.0 \%$ & $0.0 \%$ & $0.0 \%$ & & & & \\
\hline 0.2 & $0.0 \%$ & $0.0 \%$ & & & & & & 0.2 & $0.0 \%$ & $0.0 \%$ & & & & & \\
\hline 0.1 & $0.0 \%$ & & & & & & & 0.1 & $0.0 \%$ & & & & & & \\
\hline 1999 & & & & $\gamma$ & & & & 2004 & & & & $\gamma$ & & & \\
\hline 1.0 & $69.9 \%$ & $18.8 \%$ & $12.6 \%$ & $9.4 \%$ & $7.5 \%$ & $6.3 \%$ & $5.4 \%$ & 1.0 & $91.7 \%$ & $24.9 \%$ & $16.7 \%$ & $12.5 \%$ & $10.0 \%$ & $8.3 \%$ & $7.2 \%$ \\
\hline 0.9 & $53.5 \%$ & $13.9 \%$ & $9.2 \%$ & $6.9 \%$ & $5.5 \%$ & $4.6 \%$ & $4.0 \%$ & 0.9 & $69.5 \%$ & $18.0 \%$ & $12.0 \%$ & $9.0 \%$ & $7.2 \%$ & $6.0 \%$ & $5.2 \%$ \\
\hline 0.8 & $32.9 \%$ & $8.3 \%$ & $5.5 \%$ & $4.1 \%$ & $3.3 \%$ & $2.8 \%$ & & 0.8 & $40.8 \%$ & $10.3 \%$ & $6.9 \%$ & $5.1 \%$ & $4.1 \%$ & $3.4 \%$ & \\
\hline 0.7 & $7.9 \%$ & $2.0 \%$ & $1.3 \%$ & $1.0 \%$ & $0.8 \%$ & $0.7 \%$ & & 0.7 & $5.8 \%$ & $1.5 \%$ & $1.0 \%$ & $0.7 \%$ & $0.6 \%$ & $0.5 \%$ & \\
\hline 0.6 & $0.0 \%$ & $0.0 \%$ & $0.0 \%$ & $0.0 \%$ & $0.0 \%$ & & & 0.6 & $0.0 \%$ & $0.0 \%$ & $0.0 \%$ & $0.0 \%$ & $0.0 \%$ & & \\
\hline 0.5 & $0.0 \%$ & $0.0 \%$ & $0.0 \%$ & $0.0 \%$ & & & & 0.5 & $0.0 \%$ & $0.0 \%$ & $0.0 \%$ & $0.0 \%$ & & & \\
\hline 0.4 & $0.0 \%$ & $0.0 \%$ & $0.0 \%$ & $0.0 \%$ & & & & 0.4 & $0.0 \%$ & $0.0 \%$ & $0.0 \%$ & $0.0 \%$ & & & \\
\hline 0.3 & $0.0 \%$ & $0.0 \%$ & $0.0 \%$ & & & & & 0.3 & $0.0 \%$ & $0.0 \%$ & $0.0 \%$ & & & & \\
\hline 0.2 & $0.0 \%$ & $0.0 \%$ & & & & & & 0.2 & $0.0 \%$ & $0.0 \%$ & & & & & \\
\hline 0.1 & $0.0 \%$ & & & & & & & 0.1 & $0.0 \%$ & & & & & & \\
\hline 2000 & & & & $\gamma$ & & & & 2005 & & & & $\gamma$ & & & \\
\hline 1.0 & $71.0 \%$ & $19.1 \%$ & $12.8 \%$ & $9.6 \%$ & $7.7 \%$ & $6.4 \%$ & $5.5 \%$ & 1.0 & $100.0 \%$ & $34.6 \%$ & $23.1 \%$ & $17.3 \%$ & $13.9 \%$ & $11.6 \%$ & $9.9 \%$ \\
\hline 0.9 & $54.2 \%$ & $14.0 \%$ & $9.4 \%$ & $7.0 \%$ & $5.6 \%$ & $4.7 \%$ & $4.0 \%$ & 0.9 & $96.3 \%$ & $25.0 \%$ & $16.7 \%$ & $12.5 \%$ & $10.0 \%$ & $8.4 \%$ & $7.2 \%$ \\
\hline 0.8 & $32.9 \%$ & $8.3 \%$ & $5.5 \%$ & $4.1 \%$ & $3.3 \%$ & $2.8 \%$ & & 0.8 & $56.5 \%$ & $14.3 \%$ & $9.5 \%$ & $7.1 \%$ & $5.7 \%$ & $4.8 \%$ & \\
\hline 0.7 & $7.2 \%$ & $1.8 \%$ & $1.2 \%$ & $0.9 \%$ & $0.7 \%$ & $0.6 \%$ & & 0.7 & $8.1 \%$ & $2.0 \%$ & $1.3 \%$ & $1.0 \%$ & $0.8 \%$ & $0.7 \%$ & \\
\hline 0.6 & $0.0 \%$ & $0.0 \%$ & $0.0 \%$ & $0.0 \%$ & $0.0 \%$ & & & 0.6 & $0.0 \%$ & $0.0 \%$ & $0.0 \%$ & $0.0 \%$ & $0.0 \%$ & & \\
\hline 0.5 & $0.0 \%$ & $0.0 \%$ & $0.0 \%$ & $0.0 \%$ & & & & 0.5 & $0.0 \%$ & $0.0 \%$ & $0.0 \%$ & $0.0 \%$ & & & \\
\hline 0.4 & $0.0 \%$ & $0.0 \%$ & $0.0 \%$ & $0.0 \%$ & & & & 0.4 & $0.0 \%$ & $0.0 \%$ & $0.0 \%$ & $0.0 \%$ & & & \\
\hline 0.3 & $0.0 \%$ & $0.0 \%$ & $0.0 \%$ & & & & & 0.3 & $0.0 \%$ & $0.0 \%$ & $0.0 \%$ & & & & \\
\hline 0.2 & $0.0 \%$ & $0.0 \%$ & & & & & & 0.2 & $0.0 \%$ & $0.0 \%$ & & & & & \\
\hline 0.1 & $0.0 \%$ & & & & & & & 0.1 & $0.0 \%$ & & & & & & \\
\hline 2001 & & & & $\bar{\gamma}$ & & & & 2006 & & & & $\bar{\gamma}$ & & & \\
\hline 1.0 & $80.7 \%$ & $21.9 \%$ & $14.7 \%$ & $11.0 \%$ & $8.8 \%$ & $7.3 \%$ & $6.3 \%$ & 1.0 & $100.0 \%$ & $33.6 \%$ & $22.5 \%$ & $16.9 \%$ & $13.5 \%$ & $11.3 \%$ & $9.6 \%$ \\
\hline 0.9 & $61.1 \%$ & $15.9 \%$ & $10.6 \%$ & $7.9 \%$ & $6.4 \%$ & $5.3 \%$ & $4.5 \%$ & 0.9 & $93.6 \%$ & $24.3 \%$ & $16.2 \%$ & $12.2 \%$ & $9.7 \%$ & $8.1 \%$ & $7.0 \%$ \\
\hline 0.8 & $35.9 \%$ & $9.1 \%$ & $6.0 \%$ & $4.5 \%$ & $3.6 \%$ & $3.0 \%$ & & 0.8 & $55.0 \%$ & $13.9 \%$ & $9.2 \%$ & $6.9 \%$ & $5.5 \%$ & $4.6 \%$ & \\
\hline 0.7 & $5.1 \%$ & $1.3 \%$ & $0.9 \%$ & $0.6 \%$ & $0.5 \%$ & $0.4 \%$ & & 0.7 & $7.9 \%$ & $2.0 \%$ & $1.3 \%$ & $1.0 \%$ & $0.8 \%$ & $0.7 \%$ & \\
\hline 0.6 & $0.0 \%$ & $0.0 \%$ & $0.0 \%$ & $0.0 \%$ & $0.0 \%$ & & & 0.6 & $0.0 \%$ & $0.0 \%$ & $0.0 \%$ & $0.0 \%$ & $0.0 \%$ & & \\
\hline 0.5 & $0.0 \%$ & $0.0 \%$ & $0.0 \%$ & $0.0 \%$ & & & & 0.5 & $0.0 \%$ & $0.0 \%$ & $0.0 \%$ & $0.0 \%$ & & & \\
\hline 0.4 & $0.0 \%$ & $0.0 \%$ & $0.0 \%$ & $0.0 \%$ & & & & 0.4 & $0.0 \%$ & $0.0 \%$ & $0.0 \%$ & $0.0 \%$ & & & \\
\hline 0.3 & $0.0 \%$ & $0.0 \%$ & $0.0 \%$ & & & & & 0.3 & $0.0 \%$ & $0.0 \%$ & $0.0 \%$ & & & & \\
\hline 0.2 & $0.0 \%$ & $0.0 \%$ & & & & & & 0.2 & $0.0 \%$ & $0.0 \%$ & & & & & \\
\hline 0.1 & $0.0 \%$ & & & & & & & 0.1 & $0.0 \%$ & & & & & & \\
\hline
\end{tabular}

Figura A.2

Alfas ótimos para cenário com índice de Sharpe $=0,15$ 


\begin{tabular}{|c|c|c|c|c|c|c|c|c|c|c|c|c|c|c|c|}
\hline 1997 & & & & $\gamma$ & & & & 2002 & & & & $\gamma$ & & & \\
\hline D & 0.5 & 2 & 3 & 4 & 5 & 6 & 7 & D & 0.5 & 2 & 3 & 4 & 5 & $\overline{6}$ & 7 \\
\hline 1.0 & $90.2 \%$ & $26.0 \%$ & $17.4 \%$ & $13.1 \%$ & $10.5 \%$ & $8.7 \%$ & $7.5 \%$ & 1.0 & $100.0 \%$ & $32.9 \%$ & $22.1 \%$ & $16.6 \%$ & $13.3 \%$ & $11.1 \%$ & $9.5 \%$ \\
\hline 0.9 & $76.5 \%$ & $20.7 \%$ & $13.9 \%$ & $10.4 \%$ & $8.3 \%$ & $6.9 \%$ & $5.9 \%$ & 0.9 & $95.8 \%$ & $26.2 \%$ & $17.5 \%$ & $13.1 \%$ & $10.5 \%$ & $8.8 \%$ & $7.5 \%$ \\
\hline 0.8 & $57.1 \%$ & $14.8 \%$ & $9.9 \%$ & $7.4 \%$ & $5.9 \%$ & $4.9 \%$ & & 0.8 & $71.4 \%$ & $18.5 \%$ & $12.4 \%$ & $9.3 \%$ & $7.4 \%$ & $6.2 \%$ & \\
\hline 0.7 & $31.7 \%$ & $8.0 \%$ & $5.3 \%$ & $4.0 \%$ & $3.2 \%$ & $2.7 \%$ & & 0.7 & $38.9 \%$ & $9.8 \%$ & $6.5 \%$ & $4.9 \%$ & $3.9 \%$ & $3.3 \%$ & \\
\hline 0.6 & $0.5 \%$ & $0.1 \%$ & $0.1 \%$ & $0.1 \%$ & $0.0 \%$ & & & 0.6 & $0.0 \%$ & $0.0 \%$ & $0.0 \%$ & $0.0 \%$ & $0.0 \%$ & & \\
\hline 0.5 & $0.0 \%$ & $0.0 \%$ & $0.0 \%$ & $0.0 \%$ & & & & 0.5 & $0.0 \%$ & $0.0 \%$ & $0.0 \%$ & $0.0 \%$ & & & \\
\hline 0.4 & $0.0 \%$ & $0.0 \%$ & $0.0 \%$ & $0.0 \%$ & & & & 0.4 & $0.0 \%$ & $0.0 \%$ & $0.0 \%$ & $0.0 \%$ & & & \\
\hline 0.3 & $0.0 \%$ & $0.0 \%$ & $0.0 \%$ & & & & & 0.3 & $0.0 \%$ & $0.0 \%$ & $0.0 \%$ & & & & \\
\hline 0.2 & $0.0 \%$ & $0.0 \%$ & & & & & & 0.2 & $0.0 \%$ & $0.0 \%$ & & & & & \\
\hline 0.1 & $0.0 \%$ & & & & & & & 0.1 & $0.0 \%$ & & & & & & \\
\hline 1998 & & & & $\gamma$ & & & & 2003 & & & & $\gamma$ & & & \\
\hline 1.0 & $100.0 \%$ & $29.5 \%$ & $19.8 \%$ & $14.8 \%$ & $11.9 \%$ & $9.9 \%$ & $8.5 \%$ & 1.0 & $100.0 \%$ & $31.0 \%$ & $20.8 \%$ & $15.6 \%$ & $12.5 \%$ & $10.4 \%$ & $8.9 \%$ \\
\hline 0.9 & $85.8 \%$ & $23.4 \%$ & $15.7 \%$ & $11.8 \%$ & $9.4 \%$ & $7.8 \%$ & $6.7 \%$ & 0.9 & $90.2 \%$ & $24.6 \%$ & $16.5 \%$ & $12.4 \%$ & $9.9 \%$ & $8.2 \%$ & $7.1 \%$ \\
\hline 0.8 & $63.9 \%$ & $16.6 \%$ & $11.1 \%$ & $8.3 \%$ & $6.6 \%$ & $5.5 \%$ & & 0.8 & $67.2 \%$ & $17.4 \%$ & $11.6 \%$ & $8.7 \%$ & $7.0 \%$ & $5.8 \%$ & \\
\hline 0.7 & $34.8 \%$ & $8.7 \%$ & $5.8 \%$ & $4.4 \%$ & $3.5 \%$ & $2.9 \%$ & & 0.7 & $36.6 \%$ & $9.2 \%$ & $6.1 \%$ & $4.6 \%$ & $3.7 \%$ & $3.1 \%$ & \\
\hline 0.6 & $0.0 \%$ & $0.0 \%$ & $0.0 \%$ & $0.0 \%$ & $0.0 \%$ & & & 0.6 & $0.0 \%$ & $0.0 \%$ & $0.0 \%$ & $0.0 \%$ & $0.0 \%$ & & \\
\hline 0.5 & $0.0 \%$ & $0.0 \%$ & $0.0 \%$ & $0.0 \%$ & & & & 0.5 & $0.0 \%$ & $0.0 \%$ & $0.0 \%$ & $0.0 \%$ & & & \\
\hline 0.4 & $0.0 \%$ & $0.0 \%$ & $0.0 \%$ & $0.0 \%$ & & & & 0.4 & $0.0 \%$ & $0.0 \%$ & $0.0 \%$ & $0.0 \%$ & & & \\
\hline 0.3 & $0.0 \%$ & $0.0 \%$ & $0.0 \%$ & & & & & 0.3 & $0.0 \%$ & $0.0 \%$ & $0.0 \%$ & & & & \\
\hline 0.2 & $0.0 \%$ & $0.0 \%$ & & & & & & 0.2 & $0.0 \%$ & $0.0 \%$ & & & & & \\
\hline 0.1 & $0.0 \%$ & & & & & & & 0.1 & $0.0 \%$ & & & & & & \\
\hline 1999 & & & & $\gamma$ & & & & 2004 & & & & $\gamma$ & & & \\
\hline 1.0 & $85.2 \%$ & $24.3 \%$ & $16.3 \%$ & $12.2 \%$ & $9.8 \%$ & $8.1 \%$ & $7.0 \%$ & 1.0 & $100.0 \%$ & $33.1 \%$ & $22.2 \%$ & $16.7 \%$ & $13.4 \%$ & $11.1 \%$ & $9.5 \%$ \\
\hline 0.9 & $72.2 \%$ & $19.5 \%$ & $13.0 \%$ & $9.8 \%$ & $7.8 \%$ & $6.5 \%$ & $5.6 \%$ & 0.9 & $96.4 \%$ & $26.3 \%$ & $17.6 \%$ & $13.2 \%$ & $10.6 \%$ & $8.8 \%$ & $7.6 \%$ \\
\hline 0.8 & $54.4 \%$ & $14.1 \%$ & $9.4 \%$ & $7.0 \%$ & $5.6 \%$ & $4.7 \%$ & & 0.8 & $71.9 \%$ & $18.6 \%$ & $12.4 \%$ & $9.3 \%$ & $7.5 \%$ & $6.2 \%$ & \\
\hline 0.7 & $31.3 \%$ & $7.9 \%$ & $5.2 \%$ & $3.9 \%$ & $3.1 \%$ & $2.6 \%$ & & 0.7 & $39.1 \%$ & $9.8 \%$ & $6.6 \%$ & $4.9 \%$ & $3.9 \%$ & $3.3 \%$ & \\
\hline 0.6 & $2.9 \%$ & $0.7 \%$ & $0.5 \%$ & $0.4 \%$ & $0.3 \%$ & & & 0.6 & $0.0 \%$ & $0.0 \%$ & $0.0 \%$ & $0.0 \%$ & $0.0 \%$ & & \\
\hline 0.5 & $0.0 \%$ & $0.0 \%$ & $0.0 \%$ & $0.0 \%$ & & & & 0.5 & $0.0 \%$ & $0.0 \%$ & $0.0 \%$ & $0.0 \%$ & & & \\
\hline 0.4 & $0.0 \%$ & $0.0 \%$ & $0.0 \%$ & $0.0 \%$ & & & & 0.4 & $0.0 \%$ & $0.0 \%$ & $0.0 \%$ & $0.0 \%$ & & & \\
\hline 0.3 & $0.0 \%$ & $0.0 \%$ & $0.0 \%$ & & & & & 0.3 & $0.0 \%$ & $0.0 \%$ & $0.0 \%$ & & & & \\
\hline 0.2 & $0.0 \%$ & $0.0 \%$ & & & & & & 0.2 & $0.0 \%$ & $0.0 \%$ & & & & & \\
\hline 0.1 & $0.0 \%$ & & & & & & & 0.1 & $0.0 \%$ & & & & & & \\
\hline 2000 & & & & $\gamma$ & & & & 2005 & & & & $\gamma$ & & & \\
\hline 1.0 & $86.7 \%$ & $24.8 \%$ & $16.6 \%$ & $12.5 \%$ & $10.0 \%$ & $8.3 \%$ & $7.1 \%$ & 1.0 & $100.0 \%$ & $45.9 \%$ & $30.8 \%$ & $23.1 \%$ & $18.5 \%$ & $15.4 \%$ & $13.2 \%$ \\
\hline 0.9 & $73.4 \%$ & $19.9 \%$ & $13.3 \%$ & $9.9 \%$ & $8.0 \%$ & $6.6 \%$ & $5.7 \%$ & 0.9 & $100.0 \%$ & $36.5 \%$ & $24.4 \%$ & $18.3 \%$ & $14.7 \%$ & $12.2 \%$ & $10.5 \%$ \\
\hline 0.8 & $55.1 \%$ & $14.2 \%$ & $9.5 \%$ & $7.1 \%$ & $5.7 \%$ & $4.7 \%$ & & 0.8 & $99.6 \%$ & $25.8 \%$ & $17.2 \%$ & $12.9 \%$ & $10.3 \%$ & $8.6 \%$ & \\
\hline 0.7 & $31.3 \%$ & $7.9 \%$ & $5.2 \%$ & $3.9 \%$ & $3.1 \%$ & $2.6 \%$ & & 0.7 & $54.2 \%$ & $13.6 \%$ & $9.1 \%$ & $6.8 \%$ & $5.4 \%$ & $4.5 \%$ & \\
\hline 0.6 & $1.9 \%$ & $0.5 \%$ & $0.3 \%$ & $0.2 \%$ & $0.2 \%$ & & & 0.6 & $0.0 \%$ & $0.0 \%$ & $0.0 \%$ & $0.0 \%$ & $0.0 \%$ & & \\
\hline 0.5 & $0.0 \%$ & $0.0 \%$ & $0.0 \%$ & $0.0 \%$ & & & & 0.5 & $0.0 \%$ & $0.0 \%$ & $0.0 \%$ & $0.0 \%$ & & & \\
\hline 0.4 & $0.0 \%$ & $0.0 \%$ & $0.0 \%$ & $0.0 \%$ & & & & 0.4 & $0.0 \%$ & $0.0 \%$ & $0.0 \%$ & $0.0 \%$ & & & \\
\hline 0.3 & $0.0 \%$ & $0.0 \%$ & $0.0 \%$ & & & & & 0.3 & $0.0 \%$ & $0.0 \%$ & $0.0 \%$ & & & & \\
\hline 0.2 & $0.0 \%$ & $0.0 \%$ & & & & & & 0.2 & $0.0 \%$ & $0.0 \%$ & & & & & \\
\hline 0.1 & $0.0 \%$ & & & & & & & 0.1 & $0.0 \%$ & & & & & & \\
\hline 2001 & & & & $\gamma$ & & & & 2006 & & & & $\gamma$ & & & \\
\hline 1.0 & $99.0 \%$ & $29.2 \%$ & $19.5 \%$ & $14.7 \%$ & $11.7 \%$ & $9.8 \%$ & $8.4 \%$ & 1.0 & $100.0 \%$ & $44.7 \%$ & $29.9 \%$ & $22.5 \%$ & $18.0 \%$ & $15.0 \%$ & $12.9 \%$ \\
\hline 0.9 & $84.8 \%$ & $23.2 \%$ & $15.5 \%$ & $11.6 \%$ & $9.3 \%$ & $7.8 \%$ & $6.6 \%$ & 0.9 & $100.0 \%$ & $35.5 \%$ & $23.7 \%$ & $17.8 \%$ & $14.3 \%$ & $11.9 \%$ & $10.2 \%$ \\
\hline 0.8 & $63.2 \%$ & $16.4 \%$ & $10.9 \%$ & $8.2 \%$ & $6.6 \%$ & $5.5 \%$ & & 0.8 & $96.9 \%$ & $25.1 \%$ & $16.8 \%$ & $12.6 \%$ & $10.1 \%$ & $8.4 \%$ & \\
\hline 0.7 & $34.4 \%$ & $8.7 \%$ & $5.8 \%$ & $4.3 \%$ & $3.5 \%$ & $2.9 \%$ & & 0.7 & $52.7 \%$ & $13.3 \%$ & $8.8 \%$ & $6.6 \%$ & $5.3 \%$ & $4.4 \%$ & \\
\hline 0.6 & $0.0 \%$ & $0.0 \%$ & $0.0 \%$ & $0.0 \%$ & $0.0 \%$ & & & 0.6 & $0.0 \%$ & $0.0 \%$ & $0.0 \%$ & $0.0 \%$ & $0.0 \%$ & & \\
\hline 0.5 & $0.0 \%$ & $0.0 \%$ & $0.0 \%$ & $0.0 \%$ & & & & 0.5 & $0.0 \%$ & $0.0 \%$ & $0.0 \%$ & $0.0 \%$ & & & \\
\hline 0.4 & $0.0 \%$ & $0.0 \%$ & $0.0 \%$ & $0.0 \%$ & & & & 0.4 & $0.0 \%$ & $0.0 \%$ & $0.0 \%$ & $0.0 \%$ & & & \\
\hline 0.3 & $0.0 \%$ & $0.0 \%$ & $0.0 \%$ & & & & & 0.3 & $0.0 \%$ & $0.0 \%$ & $0.0 \%$ & & & & \\
\hline 0.2 & $0.0 \%$ & $0.0 \%$ & & & & & & 0.2 & $0.0 \%$ & $0.0 \%$ & & & & & \\
\hline 0.1 & $0.0 \%$ & & & & & & & 0.1 & $0.0 \%$ & & & & & & \\
\hline
\end{tabular}

Figura A.3

Alfas ótimos para cenário com índice de Sharpe $=0,2$ 


\begin{tabular}{|c|c|c|c|c|c|c|c|c|c|c|c|c|c|c|c|}
\hline 1997 & & & & $\bar{\gamma}$ & & & & 2002 & & & & $\bar{\gamma}$ & & & \\
\hline D & 0.5 & 2 & 3 & 4 & 5 & 6 & 7 & D & 0.5 & 2 & 3 & 4 & 5 & 6 & 7 \\
\hline 1.0 & $100.0 \%$ & $38.2 \%$ & $25.7 \%$ & $19.3 \%$ & $15.5 \%$ & $12.9 \%$ & $11.1 \%$ & 1.0 & $100.0 \%$ & $49.0 \%$ & $33.0 \%$ & $24.9 \%$ & $19.9 \%$ & $16.6 \%$ & $14.2 \%$ \\
\hline 0.9 & $100.0 \%$ & $33.1 \%$ & $22.2 \%$ & $16.7 \%$ & $13.4 \%$ & $11.1 \%$ & $9.6 \%$ & 0.9 & $100.0 \%$ & $42.5 \%$ & $28.5 \%$ & $21.5 \%$ & $17.2 \%$ & $14.3 \%$ & $12.3 \%$ \\
\hline 0.8 & $94.1 \%$ & $27.4 \%$ & $18.3 \%$ & $13.7 \%$ & $11.0 \%$ & $9.2 \%$ & & 0.8 & $100.0 \%$ & $35.0 \%$ & $23.5 \%$ & $17.6 \%$ & $14.1 \%$ & $11.7 \%$ & \\
\hline 0.7 & $77.2 \%$ & $20.7 \%$ & $13.8 \%$ & $10.4 \%$ & $8.3 \%$ & $6.9 \%$ & & 0.7 & $97.9 \%$ & $26.4 \%$ & $17.6 \%$ & $13.2 \%$ & $10.6 \%$ & $8.8 \%$ & \\
\hline 0.6 & $50.9 \%$ & $13.0 \%$ & $8.6 \%$ & $6.5 \%$ & $5.2 \%$ & & & 0.6 & $64.1 \%$ & $16.3 \%$ & $10.9 \%$ & $8.2 \%$ & $6.5 \%$ & & \\
\hline 0.5 & $15.0 \%$ & $3.7 \%$ & $2.5 \%$ & $1.9 \%$ & & & & 0.5 & $17.4 \%$ & $4.3 \%$ & $2.9 \%$ & $2.2 \%$ & & & \\
\hline 0.4 & $0.0 \%$ & $0.0 \%$ & $0.0 \%$ & $0.0 \%$ & & & & 0.4 & $0.0 \%$ & $0.0 \%$ & $0.0 \%$ & $0.0 \%$ & & & \\
\hline 0.3 & $0.0 \%$ & $0.0 \%$ & $0.0 \%$ & & & & & 0.3 & $0.0 \%$ & $0.0 \%$ & $0.0 \%$ & & & & \\
\hline 0.2 & $0.0 \%$ & $0.0 \%$ & & & & & & 0.2 & $0.0 \%$ & $0.0 \%$ & & & & & \\
\hline 0.1 & $0.0 \%$ & & & & & & & 0.1 & $0.0 \%$ & & & & & & \\
\hline 1998 & & & & $\gamma$ & & & & 2003 & & & & $\gamma$ & & & \\
\hline 1.0 & $100.0 \%$ & $43.9 \%$ & $29.6 \%$ & $22.3 \%$ & $17.8 \%$ & $14.9 \%$ & $12.8 \%$ & 1.0 & $100.0 \%$ & $46.1 \%$ & $31.1 \%$ & $23.4 \%$ & $18.8 \%$ & $15.6 \%$ & $13.4 \%$ \\
\hline 0.9 & $100.0 \%$ & $38.0 \%$ & $25.5 \%$ & $19.2 \%$ & $15.4 \%$ & $12.8 \%$ & $11.0 \%$ & 0.9 & $100.0 \%$ & $40.0 \%$ & $26.9 \%$ & $20.2 \%$ & $16.2 \%$ & $13.5 \%$ & $11.6 \%$ \\
\hline 0.8 & $100.0 \%$ & $31.4 \%$ & $21.0 \%$ & $15.8 \%$ & $12.6 \%$ & $10.5 \%$ & & 0.8 & $100.0 \%$ & $33.0 \%$ & $22.1 \%$ & $16.6 \%$ & $13.3 \%$ & $11.1 \%$ & \\
\hline 0.7 & $87.6 \%$ & $23.7 \%$ & $15.8 \%$ & $11.8 \%$ & $9.5 \%$ & $7.9 \%$ & & 0.7 & $92.1 \%$ & $24.9 \%$ & $16.6 \%$ & $12.4 \%$ & $10.0 \%$ & $8.3 \%$ & \\
\hline 0.6 & $57.4 \%$ & $14.6 \%$ & $9.7 \%$ & $7.3 \%$ & $5.8 \%$ & & & 0.6 & $60.4 \%$ & $15.4 \%$ & $10.2 \%$ & $7.7 \%$ & $6.1 \%$ & & \\
\hline 0.5 & $15.6 \%$ & $3.9 \%$ & $2.6 \%$ & $1.9 \%$ & & & & 0.5 & $16.4 \%$ & $4.1 \%$ & $2.7 \%$ & $2.0 \%$ & & & \\
\hline 0.4 & $0.0 \%$ & $0.0 \%$ & $0.0 \%$ & $0.0 \%$ & & & & 0.4 & $0.0 \%$ & $0.0 \%$ & $0.0 \%$ & $0.0 \%$ & & & \\
\hline 0.3 & $0.0 \%$ & $0.0 \%$ & $0.0 \%$ & & & & & 0.3 & $0.0 \%$ & $0.0 \%$ & $0.0 \%$ & & & & \\
\hline 0.2 & $0.0 \%$ & $0.0 \%$ & & & & & & 0.2 & $0.0 \%$ & $0.0 \%$ & & & & & \\
\hline 0.1 & $0.0 \%$ & & & & & & & 0.1 & $0.0 \%$ & & & & & & \\
\hline 1999 & & & & $\bar{\gamma}$ & & & & 2004 & & & & $\bar{\gamma}$ & & & \\
\hline 1.0 & $100.0 \%$ & $35.4 \%$ & $23.8 \%$ & $17.9 \%$ & $14.3 \%$ & $12.0 \%$ & $10.3 \%$ & 1.0 & $100.0 \%$ & $49.3 \%$ & $33.2 \%$ & $25.0 \%$ & $20.0 \%$ & $16.7 \%$ & $14.3 \%$ \\
\hline 0.9 & $98.1 \%$ & $30.8 \%$ & $20.7 \%$ & $15.5 \%$ & $12.4 \%$ & $10.3 \%$ & $8.9 \%$ & 0.9 & $100.0 \%$ & $42.8 \%$ & $28.7 \%$ & $21.6 \%$ & $17.3 \%$ & $14.4 \%$ & $12.4 \%$ \\
\hline 0.8 & $89.0 \%$ & $25.6 \%$ & $17.1 \%$ & $12.8 \%$ & $10.3 \%$ & $8.5 \%$ & & 0.8 & $100.0 \%$ & $35.3 \%$ & $23.6 \%$ & $17.7 \%$ & $14.2 \%$ & $11.8 \%$ & \\
\hline 0.7 & $73.0 \%$ & $19.5 \%$ & $13.0 \%$ & $9.8 \%$ & $7.8 \%$ & $6.5 \%$ & & 0.7 & $100.0 \%$ & $26.6 \%$ & $17.7 \%$ & $13.3 \%$ & $10.6 \%$ & $8.9 \%$ & \\
\hline 0.6 & $49.1 \%$ & $12.5 \%$ & $8.3 \%$ & $6.2 \%$ & $5.0 \%$ & & & 0.6 & $100.0 \%$ & $16.4 \%$ & $10.9 \%$ & $8.2 \%$ & $6.6 \%$ & & \\
\hline 0.5 & $16.6 \%$ & $4.1 \%$ & $2.7 \%$ & $2.1 \%$ & & & & 0.5 & $17.5 \%$ & $4.4 \%$ & $2.9 \%$ & $2.2 \%$ & & & \\
\hline 0.4 & $0.0 \%$ & $0.0 \%$ & $0.0 \%$ & $0.0 \%$ & & & & 0.4 & \begin{tabular}{l|l} 
\\
\end{tabular} & $0.0 \%$ & $0.0 \%$ & $0.0 \%$ & & & \\
\hline 0.3 & $0.0 \%$ & $0.0 \%$ & $0.0 \%$ & & & & & 0.3 & $0.0 \%$ & $0.0 \%$ & $0.0 \%$ & & & & \\
\hline 0.2 & $0.0 \%$ & $0.0 \%$ & & & & & & 0.2 & $0.0 \%$ & $0.0 \%$ & & & & & \\
\hline 0.1 & $0.0 \%$ & & & & & & & 0.1 & $0.0 \%$ & & & & & & \\
\hline 2000 & & & & $\gamma$ & & & & 2005 & & & & $\gamma$ & & & \\
\hline 1.0 & $100.0 \%$ & $36.3 \%$ & $24.4 \%$ & $18.3 \%$ & $14.7 \%$ & $12.2 \%$ & $10.5 \%$ & 1.0 & $100.0 \%$ & $68.4 \%$ & $46.1 \%$ & $34.7 \%$ & $27.8 \%$ & $23.2 \%$ & $19.9 \%$ \\
\hline 0.9 & $99.3 \%$ & $31.5 \%$ & $21.1 \%$ & $15.9 \%$ & $12.7 \%$ & $10.6 \%$ & $9.1 \%$ & 0.9 & $100.0 \%$ & $59.3 \%$ & $39.8 \%$ & $29.9 \%$ & $24.0 \%$ & $20.0 \%$ & $17.1 \%$ \\
\hline 0.8 & $90.5 \%$ & $26.1 \%$ & $17.5 \%$ & $13.1 \%$ & $10.5 \%$ & $8.7 \%$ & & 0.8 & $100.0 \%$ & $48.9 \%$ & $32.7 \%$ & $24.6 \%$ & $19.7 \%$ & $16.4 \%$ & \\
\hline 0.7 & $74.2 \%$ & $19.9 \%$ & $13.2 \%$ & $9.9 \%$ & $7.9 \%$ & $6.6 \%$ & & 0.7 & $100.0 \%$ & $36.9 \%$ & $24.6 \%$ & $18.4 \%$ & $14.8 \%$ & $12.3 \%$ & \\
\hline 0.6 & $49.5 \%$ & $12.6 \%$ & $8.4 \%$ & $6.3 \%$ & $5.0 \%$ & & & 0.6 & $89.4 \%$ & $22.8 \%$ & $15.2 \%$ & $11.4 \%$ & $9.1 \%$ & & \\
\hline 0.5 & $15.9 \%$ & $4.0 \%$ & $2.6 \%$ & $2.0 \%$ & & & & 0.5 & $24.3 \%$ & $6.1 \%$ & $4.0 \%$ & $3.0 \%$ & & & \\
\hline 0.4 & $0.0 \%$ & $0.0 \%$ & $0.0 \%$ & $0.0 \%$ & & & & 0.4 & $0.0 \%$ & $0.0 \%$ & $0.0 \%$ & $0.0 \%$ & & & \\
\hline 0.3 & $0.0 \%$ & $0.0 \%$ & $0.0 \%$ & & & & & 0.3 & $0.0 \%$ & $0.0 \%$ & $0.0 \%$ & & & & \\
\hline 0.2 & $0.0 \%$ & $0.0 \%$ & & & & & & 0.2 & $0.0 \%$ & $0.0 \%$ & & & & & \\
\hline 0.1 & $0.0 \%$ & & & & & & & 0.1 & $0.0 \%$ & & & & & & \\
\hline 2001 & & & & $\bar{\gamma}$ & & & & 2006 & & & & $\gamma$ & & & \\
\hline 1.0 & $100.0 \%$ & $43.4 \%$ & $29.2 \%$ & $22.0 \%$ & $17.6 \%$ & $14.7 \%$ & $12.6 \%$ & 1.0 & $100.0 \%$ & $66.5 \%$ & $44.8 \%$ & $33.7 \%$ & $27.0 \%$ & $22.5 \%$ & $19.3 \%$ \\
\hline 0.9 & $100.0 \%$ & $37.6 \%$ & $25.3 \%$ & $19.0 \%$ & $15.2 \%$ & $12.7 \%$ & $10.9 \%$ & 0.9 & $100.0 \%$ & $57.7 \%$ & $38.7 \%$ & $29.1 \%$ & $23.3 \%$ & $19.4 \%$ & $16.7 \%$ \\
\hline 0.8 & $100.0 \%$ & $31.0 \%$ & $20.8 \%$ & $15.6 \%$ & $12.5 \%$ & $10.4 \%$ & & 0.8 & $100.0 \%$ & $47.6 \%$ & $31.8 \%$ & $23.9 \%$ & $19.1 \%$ & $15.9 \%$ & \\
\hline 0.7 & $86.7 \%$ & $23.4 \%$ & $15.6 \%$ & $11.7 \%$ & $9.4 \%$ & $7.8 \%$ & & 0.7 & $100.0 \%$ & $35.9 \%$ & $23.9 \%$ & $17.9 \%$ & $14.4 \%$ & $12.0 \%$ & \\
\hline 0.6 & $56.8 \%$ & $14.5 \%$ & $9.6 \%$ & $7.2 \%$ & $5.8 \%$ & & & 0.6 & $87.0 \%$ & $22.2 \%$ & $14.8 \%$ & $11.1 \%$ & $8.8 \%$ & & \\
\hline 0.5 & $15.4 \%$ & $3.8 \%$ & $2.6 \%$ & $1.9 \%$ & & & & 0.5 & $23.6 \%$ & $5.9 \%$ & $3.9 \%$ & $2.9 \%$ & & & \\
\hline 0.4 & $0.0 \%$ & $0.0 \%$ & $0.0 \%$ & $0.0 \%$ & & & & 0.4 & $0.0 \%$ & $0.0 \%$ & $0.0 \%$ & $0.0 \%$ & & & \\
\hline 0.3 & $0.0 \%$ & $0.0 \%$ & $0.0 \%$ & & & & & 0.3 & $0.0 \%$ & $0.0 \%$ & $0.0 \%$ & & & & \\
\hline 0.2 & $0.0 \%$ & $0.0 \%$ & & & & & & 0.2 & $0.0 \%$ & $0.0 \%$ & & & & & \\
\hline 0.1 & $0.0 \%$ & & & & & & & 0.1 & $0.0 \%$ & & & & & & \\
\hline
\end{tabular}

Figura A.4

Alfas ótimos para cenário com índice de Sharpe $=0,3$ 